\title{
CARACTERIZAÇÃO MORFOLÓGICA, ESPORULAÇÃO E SENSIBILIDADE A FUNGICIDAS DE ISOLADOS DE Botrytis cinerea DE FLORES E PLANTAS ORNAMENTAIS
}

\section{PEDRO CALDARI JUNIOR}

Engenheiro Agrônomo

Orientador: Prof. Dr. HIROSHI KIMATI

Dissertação apresentada à Escola Superior de Agricultura "Luiz de Queiroz", Universidade de São Paulo, para obtenção do título de Mestre em Agronomia, Área de Concentração: Fitopatologia.

PIRACICABA

Estado de São Paulo - Brasil

Dezembro - 1998 
Dados Internacionais de Catalogação na Publicação (CIP)

DIVISĀo DE BIBLIOTECA E DOCUMENTAÇÃo - Campus "Luiz de Queiroz"/USP

Caldari Junior, Pedro

Caracterização morfológica, esporulação e sensibilidade a fungicidas de isolados de Botrytis cinerea de flores e plantas ornamentais / Pedro Caldari Junior. - - Piracicaba, 1998.

$51 \mathrm{p}$.

Dissertação (mestrado) - Escola Superior de Agricultura Luiz de Queiroz, 1998. Bibliografia.

1. Cobertura plástica 2. Efeito de luz 3. Esporulação 4. Flor 5. Fungo fitopatogênico 6. Mofo-cinzento 7. Morfologia vegetal 8. Planta ornamental 9. Resistência ao fungicida I. Titulo 
A meus pais, Pedro e Apparecida, minha esposa, Fernanda, pela compreensão e apoio,

DEDICO 


\section{AGRADECIMENTOS}

A DEUS, pois sem ele não haveria o desejo de se tentar explicar os fenômenos da natureza;

Ao Prof. Hiroshi Kimati, pela orientação dessa dissertação, conhecimentos transmitidos e pela amizade;

Aos mestres Hasime Tokeshi, Sizuo Matsuoka e Jorge A.M. Rezende, pelos conhecimentos e experiências transmitidas;

Ao Prof. Massanori Takaki da UNESP - Rio Claro, pelo empréstimo do espectroradiômetro;

Ao Prof. Antonio Augusto Franco Garcia pelo auxílio na análise dos resultados dos experimentos;

A todos os professores, funcionários e colegas do Departamento de Fitopatologia da ESALQ/USP, pelos conhecimentos e amizade;

Ao CNPq e a CAPES, pela concessão de bolsa de estudos durante o curso de Mestrado; À todos aqueles que direta ou indiretamente contribuíram para a realização deste trabalho;

Finalmente agradeço a meus pais pelos esforços para minha formação e constante incentivo. 


\section{SUMÁRIO}

Página

RESUMO

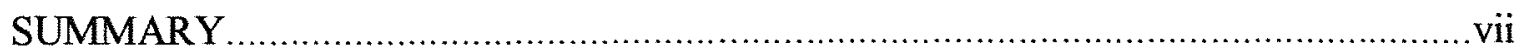

1. INTRODUÇÃO

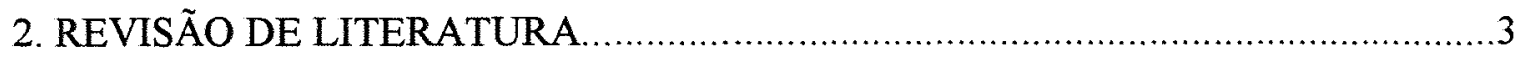

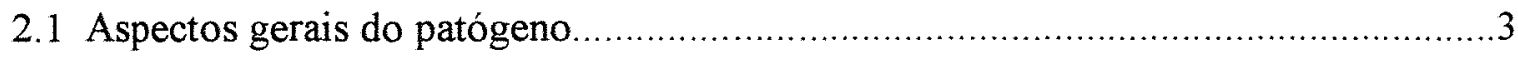

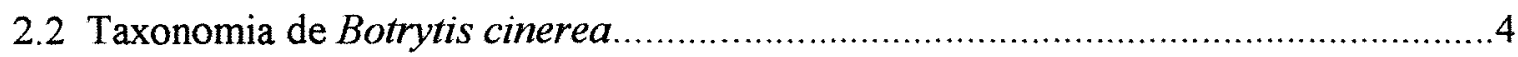

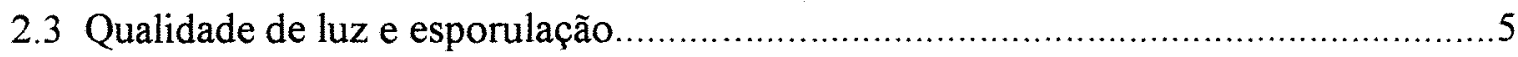

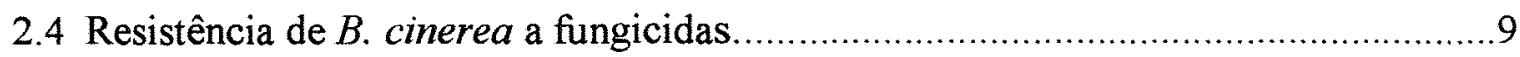

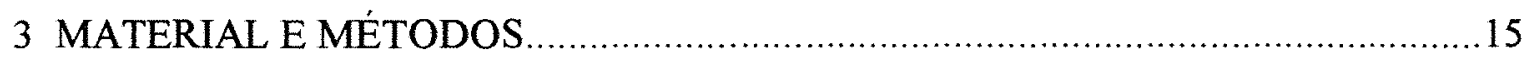

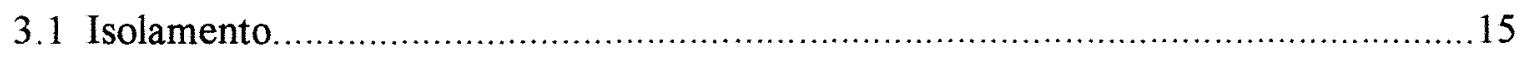

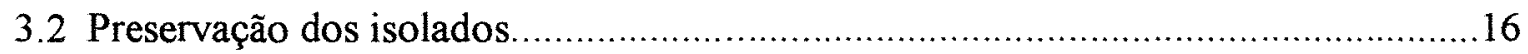

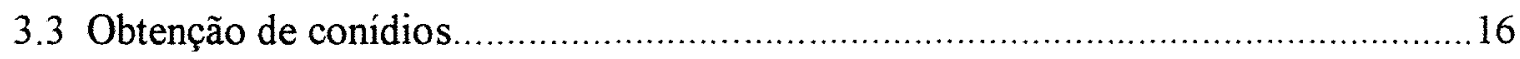

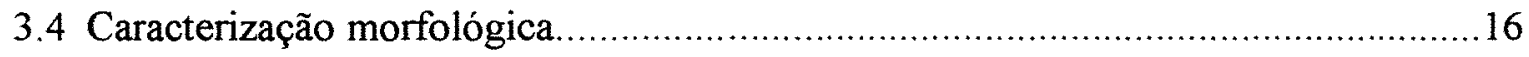

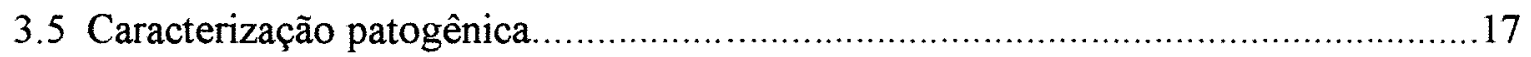

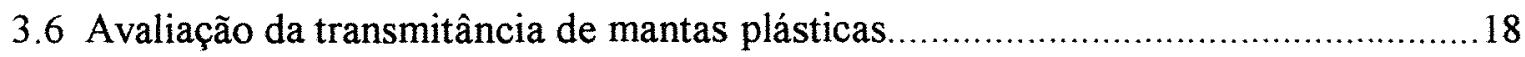

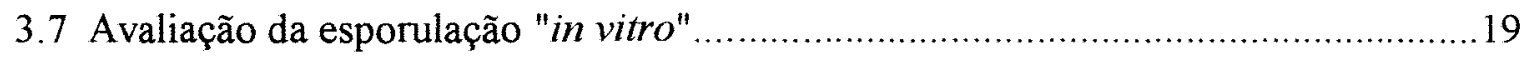

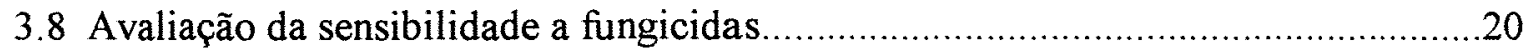

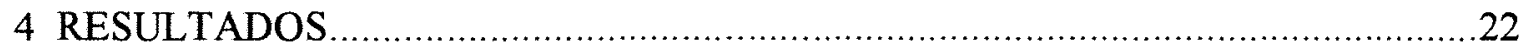

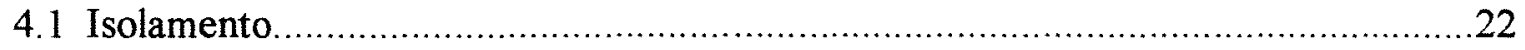

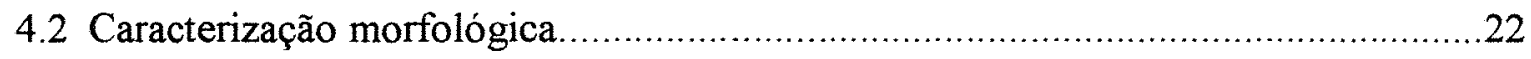

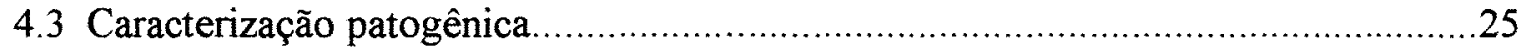

4.4 Avaliação da transmitância de mantas plásticas.....................................................26

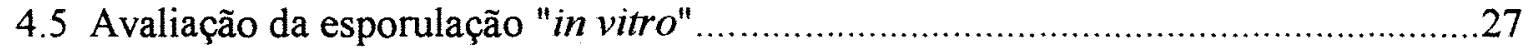

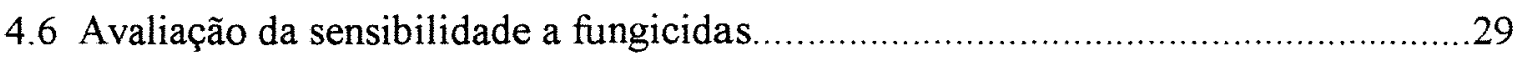

5 DISCUSSÃO

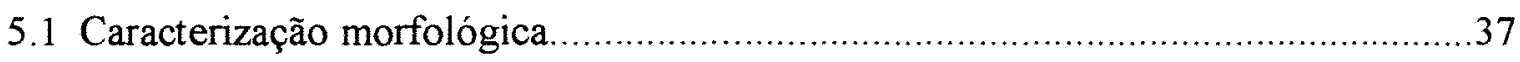

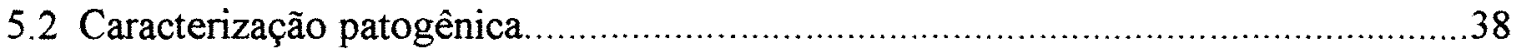


5.3 Avaliação da transmitância de mantas plásticas e da esporulação "in vitro" 39

5.4 Avaliação da sensibilidade a fungicidas. .40

6 CONCLUSÕES. .43 REFERÊNCIAS BIBLIOGRÁFICAS. 44 


\title{
CARACTERIZAÇÃO MORFOLÓGICA, ESPORULAÇÃO E SENSIBLIDADE A FUNGICIDAS DE ISOLADOS DE Botrytis cinerea DE FLORES E PLANTAS ORNAMENTAIS.
}

\author{
Autor: Pedro Caldari Junior \\ Orientador: Prof. Hiroshi Kimati
}

\section{RESUMO}

Botrytis cinerea foi isolado de plantas infectadas (predominantemente flores e ornamentais), coletadas em 5 localidades dos Estados de São Paulo e Minas Gerais.

Avaliação morfológica, medindo comprimento e largura dos conídios, com auxílio de equipamento de vídeo, possibilitou enquadrar os 10 isolados dentro de $B$. cinerea. Comparação da morfologia através da análise de "cluster" mostrou que isolados de localidades próximas apresentam maior similaridade que aqueles obtidos de localidades distantes. Teste de patogenicidade, inoculando-se flores, frutos e folhas destacadas, sob condições controladas (alta umidade e temperatura de $20^{\circ} \mathrm{C}$ ) não mostrou diferença entre os isolados.

A esporulação de 9 dos 10 isolados de $B$. cinerea foi inibida, "in vitro", pela cobertura das placas de Petri com filmes plásticos de polietileno aditivado e PVC azul, mas não com cobertura de polietileno, mostrando o potencial de controle da doença pelos 2 primeiros tipos de filmes.

A sensibilidade dos isolados a benomyl, iprodione, difenoconazole e azoxystrobin, nas concentrações de $0,0.1,1,10,100$ e 100 ppm, foi avaliada em teste de crescimento micelial, pelo método do fungicida incorporado ao meio de BDA. Resistência a benomyl foi detectada nos 10 isolados; apenas 1 isolado apresentou resistência simultânea a iprodione, dois ao difenoconazole; para azoxystrobin os resultados obtidos não permitiram conclusão satisfatória. 


\section{MORPHOLOGICAL CARACTERIZATION, SPORULATION AND \\ FUNGICIDE SENSITIVITY OF ISOLATES OF Botrytis cinerea FROM FLOWERING AND ORNAMENTAL PLANTS}

Author: Pedro Caldari Junior

Adviser: Prof. Hiroshi Kimati

\section{SUMMARY}

Botrytis cinerea was isolated from infected flowering and ornamental plants in 5 different localities in the States of São Paulo and Minas Gerais.

Morphological evaluation based on spore length and width, measured with video equipment, suggests that all ten isolates could be grouped into $B$. cinerea. Morphological comparison by cluster analysis showed greater similarity among isolates from the same geographical area, independent of the host species, than from different regions. Pathogenicity tests on detached inoculated flowers, leaves and fruits from different host species, under controlled condition (high relative humidity and $20^{\circ} \mathrm{C}$ ), did not show difference among isolates.

Sporulation of nine out of ten isolates of $B$. cinerea was inhibited, in vitro, covering Petri dishes with plastic films containing additives that absorbed nearultraviolet (n-UV) light in the range of $200-400 \mathrm{~nm}$. This result shows the potential use of $\mathrm{n}-\mathrm{UV}$ films for the control of gray mold in greenhouse crops.

Sensitivity of $B$. cinerea isolates to different concentration $(0,0.1,1,10,100$, $1000 \mathrm{ppm}$ ) of benomyl, iprodione, difenoconazole, and azoxystrobin was tested in mycelial growth experiments. All ten isolates were resistant to benomyl, one isolate was resistant to benomyl and iprodione, two were resistant to difenoconazole. No conclusive results were obtained to azoxystrobin. 


\section{INTRODUÇÃO}

A floricultura brasileira, atividade comercial de pouco mais de meio século, movimenta anualmente 700 a 800 milhões de dólares, concentrando-se nas regiões sudeste e sul, onde São Paulo desponta como responsável por $70 \%$ da produção do país, com área cultivada de mil hectares e 2.500 produtores (Almeida \& Aki, 1995).

Com forte tendência de crescimento, a produção de flores e plantas ornamentais enfrenta graves entraves ao seu desenvolvimento, sendo um dos principais o controle fitossanitário. Tratam-se de produtos altamente perecíveis, vendidos pela atração visual, sendo portanto primordial, para o sucesso da comercialização, a ausência, quase que por completo, de danos decorrentes de pragas e doenças.

Dentre os problemas fitossanitários do cultivo de flores e plantas ornamentais, destacam-se as doenças fúngicas, e dentre estas a causada pelo fungo Botrytis cinerea Pers. ex Fr., que possui ampla gama de hospedeiros, incluindo mais comumente a violetaafricana, a begônia, o crisântemo, a roseira, o cravo, a poinsettia, etc. (Coley-Smith et al, 1980; Agrios, 1988; Kerssies, 1994).

B. cinerea encontra-se distribuido em todo mundo, ocorrendo com grande freqüência em cultivos intensivos, principalmente em casas de vegetação, onde predomina a produção de flores e plantas ornamentais.

O clima das casas de vegetação, segundo Jarvis (1992), é essencialmente ameno, úmido e livre de vento, ideal para o desenvolvimento de várias pragas e doenças proporcionando ambiente favorável à produção vegetal durante o ano todo, mas possibilitando também que patógenos, como $B$. cinerea, se desenvolvam de maneira satisfatória, ocasionando grandes perdas, sendo o maior interesse dos fitopatologistas 
controlar o ambiente a fim de evitar as epidemias. Nessas condições controladas e de agricultura intensiva, a descontinuidade de inóculo entre os cultivos é fato, sendo medidas que impeçam a produção do mesmo imprescindíveis, citando como exemplo a inibição da esporulação por meio de mantas plásticas fotoseletivas (Honda et al., 1977; Sasaki et al., 1985; Ramírez \& Torres, 1995; Nicot et al., 1996).

Pela necessidade de produtos isentos de danos, os produtores de flores e plantas ornamentais em casas de vegetação, utilizam de maneira intensiva o controle químico, fato este que aliado à maior especificidade dos fungicidas modernos, pode favorecer e acelerar o surgimento de populações de fungos resistentes a fungicidas.

Isolados de $B$. cinerea obtidos de cultivos comerciais de diferentes plantas apresentam, com freqüência, resistência a fungicidas, principalmente aos benzimidazóis e dicarboximidas, podendo em alguns casos esta resistência ser a ambos os grupos químicos (resistência cruzada), sendo o surgimento de resistência, no caso deste patógeno, muito rápida (Katan, 1982; Fraile et al, 1986; Northover \& Matteoni, 1986; Rewal et al, 1991; Moorman et al, 1992; Kerssies, 1993; Kimati, 1995; Raposo et al, 1996).

Para a produção isenta de danos causados por $B$. cinerea, deve-se buscar o controle através da integração de vários métodos, o que reduz o risco do surgimento de resistência a fungicidas nas populações do patógeno, fato comum em cultivos intensivos que tenham estratégia de controle baseada exclusivamente no controle químico (uso intensivo de fungicidas).

O presente trabalho, visando aprofundar os conhecimentos a respeito do patógeno B. cinerea, tem como objetivos:

1. Caracterizar morfologicamente isolados do fungo oriundos de diferentes hospedeiros hortícolas.

2. Caracterizar patogenicamente os isolados.

3. Avaliar a esporulação desses isolados sob diferentes condições de iluminação.

4. Avaliar a sensibilidade dos isolados a diferentes grupos de fungicidas. 


\section{REVISÃO DE LITERATURA}

\subsection{Aspectos gerais do patógeno}

Botrytis cinerea Pers. ex Fr., estágio imperfeito do ascomiceto da ordem Helotiales, Botryotinia fuckeliana (de Bary) Whetzel, é o agente causal de doenças conhecidas como mofo cinzento ("gray mold") e queima de botrytis ("botrytis blight") em diversas flores e plantas ornamentais. Encontra-se distribuído pelo mundo todo e onipresente em casas de vegetação, sendo uma das doenças mais comuns nessas condições (Katan, 1982; Agrios, 1988; Jarvis, 1992; Kerssies, 1994; Daughtrey et al, 1995; Kerssies et al., 1995; Krugner \& Bacchi, 1995). Poinsettia (Euphorbia pulcherrima Willd. ex Klotzsch), cyclamen (Cyclamen persicum Mill), gérbera (Gerbera jamesonii H. Bolus ex Adlam), gerânio (Pelargonium spp.), rosa (Rosa spp.), são alguns exemplos de flores e plantas ornamentais hospedeiras de B. cinerea (Horst, 1983; Kerssies, 1994; Daughtrey et al., 1995; Kerssies et al., 1995).

As perdas decorrentes da incidência de mofo cinzento, causado por $B$. cinerea, em gerânios no mundo no ano de 1985, corresponderam, segundo estimativas citadas por Daughtrey et al (1995), a cifras entre 5,1 a 7,6 milhões de dólares. Em hastes de rosa a infecção de B. cinerea reduz totalmente seu valor ornamental (Hazendonk et al., 1995), inviabilizando sua comercialização. 


\subsection{Taxonomia de Botrytis cinerea}

Ascomicetos da ordem Helotiales são diferenciados pelas características de seus anamorfos, sendo portanto o gênero Botryotinia, diferenciado através dos caracteres do gênero Botrytis (Elliott, 1964; Krugner \& Bacchi, 1995).

B. cinerea produz micélio abundante, de coloração pardo acinzentada, com conidióforos longos e ramificados alternadamente, mais freqüentemente na região apical. Células conidiógenas terminais apresentam-se nas extremidades das ramificações, onde conídios unicelulares, multinucleados ( 3 a 18 núcleos, média de 5), hialinos ou quase hialinos, lisos e globosos encontram-se ligados. $\mathrm{O}$ arranjo dos conídios nos conidióforos dão o nome ao gênero, pois botrys, palavra de origem grega, significa "cacho de uvas". A massa de conídios possui coloração típica, marrom acinzentada. A produção de conídios é abundante, tanto em meios de cultura como em tecidos de hospedeiros infectados. Forma escleródios bem desenvolvidos, de coloração negra tanto em meio de cultura com em restos culturais, que determinam a sobrevivência do patógeno em condições adversas (Hancock \& Lorberr, 1963; Epton \& Richmond, 1980; Jarvis, 1980; Ghini, 1984; Agrios, 1988; Araújo, 1995; Krugner \& Bacchi, 1995).

As dimensões dos conídios de $B$. cinerea podem variar de 7-10 $\mu \mathrm{m}$ de largura e 9$14 \mu \mathrm{m}$ de comprimento(Hancock \& Lorberr, 1963; Crowe et al., 1994), 6-9 $\mu \mathrm{m} \times 9-17$ $\mu \mathrm{m}$ (Morgan, 1971) 8-10 $\mu \mathrm{m} \times 10-12 \mu \mathrm{m}$ (Bulit \& Dubos, 1988), 6-9 $\mu \mathrm{m} \times 8-14 \mu \mathrm{m}$ (Daughtrey et al., 1995). Quanto à forma, podem ser elipsóides a ovóides ou globosos.

Ghini (1984), em experimento de caracterização morfológica de 71 isolados de diferentes espécies de Botrytis da cebola, efetuou medições de comprimento e largura de conídios, obtendo diferenciação entre $B$. cinerea, $B$. allii e $B$. squamosa, pela comparação das médias das freqüências daqueles parâmetros. Os conídios de $B$. cinerea segundo a autora, possuíam em média $11,22 \mu \mathrm{m}$ de comprimento e $6,75 \mu \mathrm{m}$ de largura, dimensões estas distintas de $B$. allii e $B$. squamosa, que em média mediam $10,66 \mu \mathrm{m} \times 5,41 \mu \mathrm{m} \mathrm{e}$ $19,37 \mu \mathrm{m} \times 12 \mu \mathrm{m}$, respectivamente. 
Informações adicionais, mostram que conídios de $B$. squamosa possuem dimensões entre 12-15 $\mu \mathrm{m} \times 15-22 \mu \mathrm{m}$ (Lacy \& Lorbeer, 1994), 14-23 $\mu \mathrm{m} \times 11-16 \mu \mathrm{m}$ (Hancock \& Lorbeer, 1963), além de formato globoso ou esferoidal, não septados. Já $B$. allii apresenta as dimensões dos conídios geralmente entre 5-6 $\mu \mathrm{m} \times 7-11 \mu \mathrm{m}$, com formato ovóide e hialinos (Hancock \& Lorbeer, 1963; Lacy \& Lorbeer, 1994).

As dimensões dos conídios, segundo Ghini (1984), apesar de possibilitar a identificação de espécies de Botrytis, não constituem critério rigoroso para diferenciação das mesmas, devido à semelhança entre essas dimensões entre espécies, como por exemplo $B$. cinerea e $B$. allii. Apesar desse comentário a autora conclui em seu trabalho que as espécies de Botrytis podem ser distinguidas através de sua morfologia.

\subsection{Qualidade de luz e esporulação}

Alguns fungos fitopatogênicos, como por exemplo Alternaria spp., Botrytis spp. e Stemphylium sp., possuem como característica, maior esporulação quando expostos a faixas de radiação ultravioleta (abaixo de $360 \mathrm{~nm}$ ). Por outro lado, para outros fungos, comprimentos de onda na faixa de 290 a $320 \mathrm{~nm}$ atuam de modo negativo, diminuindo a sobrevivência e viabilidade de seus propágulos, citando como exemplo basidiosporos de Exobasidium vexans causador de queima em plantas de chá (Gunasekera et al., 1996). A primeira característica possibilita, em condições de casa de vegetação cobertas com materiais que bloqueiem a passagem de comprimentos de onda menores que $390 \mathrm{~nm}$, o controle de doenças causadas por aqueles (Sasaki et al, 1985; Agrios, 1988; Ghini \& Bettiol, 1995). A segunda, pode colaborar na regulação natural de algumas doenças, através da exposição de esporos fúngicos a esses comprimentos de onda de modo a afetar sua longevidade (Rotem et al., 1985).

De acordo com Hite (1973) a radiação próxima do ultravioleta é um fator limitante na esporulação (fase assexuada) do fungo B. cinerea "in vitro". Também segundo o autor a propriedade de transmissão desse espectro de radiação por vidros temperados e materiais plásticos está intimamente associada com a quantidade de 
esporulação do fungo. Para $B$. cinerea, a radiação visível tem pouco ou nenhum efeito sobre a esporulação, ao contrário da radiação próxima do ultravioleta que a estimula, enquanto que a ausência de luz permite a produção de escleródios.

Filmes plásticos contendo aditivos que alterem a transmissão do espectro de luz podem ser ferramentas úteis no controle de patógenos de parte aérea em cultivos sob casas de vegetação (Nicot et al., 1996).

Apesar da esporulação "in vitro" de muitos fungos ocorrer apenas no escuro, eles não esporulam se não forem expostos a breve período de luz ultravioleta, solar ou de outra fonte luminosa. Já outros, são estimulados a esporular "in vitro" quando o meio se torna pobre em nutrientes (Rotem et al., 1978).

A luz do dia contém comprimentos de onda próximos do ultravioleta em seu espectro e estas tem demonstrado seu efeito fotoesporogênico, evidenciando que vários fungos utilizam os comprimentos de onda próximos do ultravioleta como um gatilho para dar inicio ao seu processo reprodutivo, estando também, do ponto de vista ecofisiológico, esses comprimentos de onda, associados com condições inconvenientes para o desenvolvimento vegetativo de alguns fungos. Para que a fotoesporogênese ocorra, algumas substâncias produzidas por esses fungos (pigmentos) podem estar envolvidas, atuando como fotoreceptores (Leach, 1964; Leach, 1965; Manning \& Tiedemann, 1995). Dessa forma verifica-se a importância da luz, principalmente de sua qualidade, no processo de conidiogênese do fungo $B$. cinerea.

Leach (1962) trabalhando com 34 espécies de fungos, que foram irradiadas de forma contínua com fonte luminosa de comprimentos próximos do ultravioleta, concluiu que esses comprimentos de onda são importantes na esporulação. Também verificou que irradiações de comprimentos de onda próximos do ultravioleta são transmitidas eficientemente através de vidraria tipo "Pirex", que lâmpadas fluorescentes do tipo "luz do dia" irradiam quantias significativas de comprimentos de onda próximos do ultravioleta e que lâmpadas incandescentes emitem muito pouca luz ultravioleta. 
Em experimento similar Hite (1973) também verificou que a esporulação de $B$. cinerea ocorreu de maneira satisfatória quando em cultura em placas de Petri de vidro tipo "Pirex" e de plástico ("polyvinilfluoride").

Irradiações de comprimentos de onda próximos do ultravioleta $(320-380 \mathrm{~nm})$ são rotineiramente utilizadas para indução de esporulação de $B$. cinerea e outros fungos em cultura, tendo esse fungo requerimento luminoso para sua reprodução assexuada (formação de conídios) (Clark \& Lorbeer, 1973; Colhoun, 1973; Hite, 1973; Honda, 1977).

Leach (1962) avaliou a esporulação de $B$. cinerea, entre outros fungos, em diferentes meios de cultura e condições de iluminação. Esse fungo apresentou, nos quatro meio de cultura utilizados (BDA, "malt extract agar", "Czapek's agar" e agar-água), esporulação muito pequena, quando mantido no escuro, e abundante sob condições de iluminação contínua com comprimentos de onda próximos do ultravioleta, o que levou a concluir que a composição do meio de cultura não apresenta efeito na esporulação das colônias irradiadas.

Honda et al. (1977) avaliaram a esporulação de mais de 200 isolados de $B$. cinerea de abóbora, berinjela, tomateiro e roseira sob diferentes condições de iluminação, sendo ela abundante sob iluminação contínua e nula ou mínima, na ausência completa de luz. Os mesmos autores efetuaram teste de esporulação de 5 isolados do fungo, recobrindo as placas de Petri com várias mantas plásticas com baixa transmissão de comprimentos de onda entre 200 e $400 \mathrm{~nm}$ e colocando-as novamente sob iluminação contínua. A esporulação não ocorreu nos tratamentos com mantas plásticas de baixa transmissão de comprimentos de onda menores que $345 \mathrm{~nm}$.

Sasaki et al.(1985) realizaram experimentos em casas de vegetação com cenoura, tomate, pimenta vermelha, pimentão, aspargo e cebolinha, objetivando avaliar o manejo de doenças através do controle da qualidade da luz incidente nessas casas de vegetação. Os patógenos avaliados foram: Alternaria dauci, A. porri, A. brassicae, A. solani, Botrytis squamosa e Stemphylium botryosum. Os filmes de cobertura das casas de vegetação utilizados foram filme aditivado para limitar a transmissão de comprimentos de 
onda de $390 \mathrm{~nm}$ e filme plástico comum, que permitia a passagem de comprimentos de onda de até $300 \mathrm{~nm}$. Os resultados obtidos mostraram a supressão das doenças causadas pelos seis fungos na casa de vegetação coberta com o filme aditivado em relação aquela coberta com o filme não aditivado, principalmente pela redução na esporulação dos patógenos citados.

Vakalounakis (1992) avaliou o efeito de diferentes tipos de mantas plásticas, usadas na cobertura de casas de vegetação, sobre a incidência de três doenças do tomateiro (pinta preta, mancha de Cladosporium e mofo cinzento). $O$ experimento foi conduzido em casas de vegetação cobertas com diferentes tipos de mantas plásticas. A primeira foi coberta com filme de polietileno com limite de transmissão para comprimentos de onda de $385 \mathrm{~nm}$, e a outra com limite de transmissão para comprimentos de onda de $340 \mathrm{~nm}$. Ambas as coberturas possibilitavam transmissão ao redor de $85 \%$ da luz na região do visível. Foram avaliados dois ciclos produtivos, sendo o índice médio de doença no primeiro e segundo ciclo de $52 \%$ e $40 \%$, respectivamente, na casa de vegetação coberta com a manta plástica com limite de transmissão para comprimentos de onda de $385 \mathrm{~nm}$ em relação à segunda estufa coberta com manta com limite de transmissão para comprimentos de onda de $340 \mathrm{~nm}$. Esse resultado evidencia que a eliminação de comprimentos de onda menores que $330 \mathrm{~nm}$ em cultivos em casas de vegetação proporciona o controle de doenças causadas por esses patógenos que tem sua esporulação afetada ou inibida pela ausência de tais comprimentos de onda.

O fungo $B$. cinerea tem melhor esporulação sob luz de comprimento de onda de $355 \mathrm{~nm}$ e, tendo, alguns tipos de cobertura de estufa, a propriedade de filtrar esse comprimento de onda, podem ser recomendados no controle da esporulação do patógeno em casas de vegetação onde existam roseiras, hospedeiras comuns desse patógeno (Horst, 1983).

Visando estudar alternativas para o controle de $B$. cinerea, muito freqüente em cultivos comerciais de roseira em Bogotá, Colômbia, Ramírez \& Torres (1995) compararam o efeito de mantas plásticas, uma de plástico normal (não aditivado) com outra de plástico fotoseletivo (com pigmento capaz de filtrar a luz ultravioleta), na 
incidência de mofo cinzento em casas de vegetação similares às comercialmente utilizadas naquele país. Observaram que a incidência da doença nas variedades "Madame Delbard" e "Eterna", foi muito maior na casa de vegetação coberta com plástico normal. Observaram também que a densidade de esporos no ar era menor sob plástico fotoseletivo, o que explica a menor incidência da doença em roseiras sob essa cobertura.

Nicot et al. (1996) verificaram a influência de filmes plásticos com propriedade de filtrar o espectro luminoso e bloquear comprimentos de onda próximos do ultravioleta $(280$ a $380 \mathrm{~nm})$, sobre a germinação de esporos, crescimento micelial e esporulação do fungo $B$. cinerea em condições de laboratório. O ensaio para verificação do crescimento micelial e esporulação consistiu no recobrimento de placas com BDA + disco de micélio do fungo com diferentes filmes plásticos, tendo alguns deles aditivos com propriedade de filtrar comprimentos de onda próximos do ultravioleta. O teste de germinação de esporos foi efetuado com a inoculação de placas contendo meio BDA com suspensão de esporos $\left(10^{7}\right.$ esporos $\left./ \mathrm{ml}\right)$. As placas foram colocadas sob lâmpadas fluorescentes do tipo "luz do dia", distanciadas dessa fonte de $95 \mathrm{~cm}$. O crescimento micelial e a germinação de esporos não foram afetados pelo tipo de filme plástico. Já a produção de esporos após 9 dias de incubação foi muito reduzida nos tratamentos onde se utilizaram filmes plásticos com propriedade de filtrar os comprimentos de onda próximos do ultravioleta.

\subsection{Resistência de $B$. cinerea a fungicidas}

Resistência de fungos a fungicidas pode ser definida, segundo Dekker (1995), como sendo o ajuste estável e hereditário de um fungo a um fungicida, resultando na sua menor sensibilidade a este fungicida, podendo a tolerância ser entendida como um sinônimo. Já resistência cruzada, conforme esse autor, é a resistência a dois ou mais fungicidas, mediada pelo mesmo fator genético.

Os fungos, de acordo com Kimati (1995), são, como todos os demais organismos vivos, geneticamente maleáveis, permitindo, através de mutações tornar-se resistentes a fungicidas específicos, que atuam em um ou poucos processos metabólicos vitais. 
Mutações em fungos ocorrem numa freqüência de 1 em $10^{4}$ a 1 em $10^{9}$, podendo os fungicidas selecionar os mutantes resistentes a um ou mais fungicidas, tendo papel importante nesse surgimento de resistência a pressão de seleção.

A utilização de fungicidas favorece as células resistentes pela eliminação das sensíveis. O fungicida por si só não induz resistência, mas atua como agente selecionador. Se um fungicida particular parece ser mutagênico, ele não deve ser utilizado em culturas alimentícias. Quando sob pressão de seleção de um fungicida, população resistente de um patógeno pode surgir, resultando em falhas no controle da doença. Isto tem ocorrido rotineiramente, especialmente após a introdução, nos anos sessenta, dos fungicidas específicos, dos quais muitos eram sistêmicos (Dekker, 1995).

Espécies de Monilinia, incluindo M. fructicola, são heterocarióticas, possuindo 40 ou mais núcleos por hifa, sendo a exposição contínua a fungicidas do grupo dichloronitroanilina e a habilidade de vários isolados em sobreviver na presença desses fungicidas, fatores de predisposição para a seleção de hifas resistentes. Processo similar, segundo Ritchie (1982), pode ocorrer para o fungicida dichloran e os fungos Rhizopus stolonifer e B. cinerea.

$O$ desenvolvimento de resistência a fungicidas em $B$. cinerea, segundo Maude (1980) ocasiona falhas no controle da doença e grandes perdas econômicas pela redução quantitativa e qualitativa da produção vegetal. Também de acordo com o autor, para que isso ocorra, e geralmente ocorre no caso de $B$. cinerea, a população resistente deve ser geneticamente estável e dominante, além de virulenta e agressiva e igualmente competitiva em relação a populações sensíveis.

A falha no controle do mofo cinzento com vinclozolin e dicarboximidas (ambos dicarboximidas) em cultivos em casas de vegetação pode ser atribuída, segundo Katan (1982), ao desenvolvimento de resistência a esses fungicidas nas populações do patógeno $B$. cinerea. Esse autor comparou isolados insensiveis provenientes de culturas mantidas em laboratório e nunca expostas aos fungicidas citados com isolados provenientes de casas de vegetação onde o uso de tais produtos era constante. Conídios de isolados sensíveis não germinavam em meio BDA contendo $5 \mu \mathrm{g} / \mathrm{ml}$ dos fungicidas, já os conídios 
de isolados de casas de vegetação germinavam normalmente em meio BDA contendo $100 \mu \mathrm{g} / \mathrm{ml}$ de vinclozolin. Esses resultados aparentemente mostram que o surgimento de resistência é resultado da pressão de seleção imposta sobre a população do patógeno pelo uso intensivo e exclusivo de fungicidas do grupo dos dicarboximidas em condições favoráveis a epidemias de mofo cinzento, comuns em casas de vegetação.

Fraile et al. (1986), obtiveram resultado semelhante ao de Katan, em estudo realizado com 104 isolados de $B$. cinerea provenientes também de cultivos intensivos em casas de vegetação. Do total de isolados, $67 \%$ apresentavam resistência a fungicidas do grupo dos dicarboximidas, podendo esse surgimento surgir após o uso desses fungicidas por apenas um ano, bem como após vários anos. Outro resultado importante desse trabalho é que isolados resistentes crescem mais vagarosamente em meio de cultura BDA em comparação com isolados sensíveis, mas os isolados resistentes provenientes de casas de vegetação onde o uso de dicarboximidas era mais intenso, apresentaram maior esporulação e germinação de esporos em meio de cultura BDA com fungicida de que isolados sensiveis, fato esse que podem ter importante influência na epidemiologia da doença em cultivos em casas de vegetação onde o uso de dicarboximidas é rotineiro.

Quando populações de $B$. cinerea são repetidamente expostas a fungicidas com modo de ação sobre sítios específicos, cepas resistentes podem ser prontamente selecionadas, sendo o resultado dessa seleção facilmente encontrado, no caso dos benzimidazóis e dicarboximidas, em casas de vegetação onde o cultivo é intensivo (Moorman \& Lease, 1992). Resistência de populações de Botrytis a benomyl, segundo esses autores, foi primeiramente observada em cultivo da planta ornamental cyclamen em casa de vegetação. Também os autores citam que a resistência nessas populações estabiliza-se numa porcentagem muito grande e persiste por muitos anos após cessar-se o uso de benomyl. Já a resistência cruzada a benzimidazóis e dicarboximidas, vem sendo relatada desde 1979.

Northoever \& Matteoni (1986) detectaram população resistente a benzimidazóis e dicarboximidas de $B$. cinerea em parreirais no sul do estado de Ontario, nos E.U.A. Essa população resistente foi detectada após 7 (ou até menos) pulverizações de benomyl 
(benzimidazol) e, no caso de iprodione ou vinclozolin (dicarboximidas), após 10 ou mais pulverizações. No caso de cultivos em casas de vegetação, após 5 anos de uso periódico de iprodione, o fungo já havia desenvolvido resistência ao fungicida. Exposições ocasionais a iprodione, também em condições de casa de vegetação, segundo o trabalho desses autores, diminuem muito a chance de desenvolvimento de resistência em populações (freqüência de 0 a $5 \%$ ) desse fungo quando comparado com exposições regulares (freqüência de 35 a 96\%).

Gullino et al. (1989) estudaram por um período de 3 anos população de $B$. cinerea em parreirais italianos, sob diferentes esquemas de pulverização, a fim de avaliar a proporção de resistentes aos fungicidas benzimidazóis e dicarboximidas. Os resultados do experimento mostraram que $70 \%$ dos isolados avaliados apresentavam resistência a ambos os fungicidas citados (resistência cruzada), resultando em decréscimo na eficácia dos fungicidas do grupo dos dicarboximidas no controle da doença. Também houve um aumento no número de isolados resistentes após aplicações desse grupo de fungicidas. Pulverizações ( 2 por estação de cultivo) combinadas de benzimidazol com diethofencarb, alternadas com dicarboximidas, promoveram controle satisfatório da doença, além de decréscimo na porcentagem de isolados resistentes a benzimidazóis. Já a combinação de thiram e procymidone, apesar de controlar a doença, incrementaram o número de isolados resistentes a dicarboximidas na população.

Num estudo efetuado no Reino Unido por Rewal et al. (1991), verificou-se que de 489 isolados de $B$. cinerea de cultivos em casas de vegetação, $67,3 \%$ dos mesmos mostravam-se resistentes a benomyl e 45,6\% a vinclozolin. Após esse levantamento esse grupo de pesquisadores avaliou a sensibilidade desses isolados ao fungicida diclofluanid, muito utilizado por produtores para o controle do mofo cinzento. Encontrou-se que alguns isolados do fungo também apresentaram resistência a esse fungicida de grupo químico diferente, possuindo alguns isolados obtidos no campo resistência cruzada a vinclozolin e outros, obtidos durante os estudos populacionais, não. Essa observação, e a de que essas populações resistentes a vinclozolin e dichlofluanid eram pouco competitivas, indicam que para o fungicida dichlofluanid, mesmo existindo o problema de resistência, 
não existe ameaça na sua utilização no controle do mofo cinzento, fato esse que não se aplica aos fungicidas benomyl e vinclozolin.

Moorman \& Lease (1992), efetuando levantamento da existência de populações resistentes de $B$. cinerea em cultivos de flores e plantas ornamentais na Pennsylvania (EUA), verificaram que em todos os cultivos visitados (todos em casas de vegetação) foram isoladas populações resistentes a benzimidazóis., e que em $50 \%$ desses cultivos encontrou-se resistência cruzada a benzimidazóis e dicarboximidas. Vale salientar que em levantamento prévio efetuado pelos autores, $90 \%$ desses cultivos de flores e plantas ornamentais utilizavam fungicidas benzimidazóis e 30\% dicarboximidas como produtos base de esquema de pulverização semanal.

Também objetivando verificar a sensibilidade de populações de $B$. cinerea a fungicidas triazóis, benomyl e vinclozolin, Stehmann \& De Waard (1996) efetuaram teste com 121 isolados do fungo de diversos países (França, Alemanha, Israel e Holanda). Os resultados obtidos mostraram que $100 \%$ dos isolados apresentavam resistência a benomyl (benzimidazol) e $71 \%$ a vinclozolin (dicarboximida). Os triazóis proporcionaram inibição do crescimento micelial para a maioria dos isolados, apesar de alguns isolados da Alemanha, coletados em 1992, mostrarem-se pouco sensíveis a esse grupo de fungicidas (inibidores da síntese de esteróis, ou DMI). Essas populações resistentes aos fungicidas DMI, contribuem para a limitação da performance desse grupo de fungicidas em condições de campo.

Para estimar a frequiência de resistência em $B$. cinerea a fungicidas em produções de olerícolas em casas de vegetação no sudoeste da Espanha, Raposo et al. (1996), efetuaram coleta do fungo, num total de 216 isolados, de 49 casas de vegetação diferentes. Nesses locais de origem dos isolados, os produtores aplicavam fungicidas baseando-se num calendário fixo, sendo uma pulverização a cada 7 dias, visando o controle do mofo cinzento. Os fungicidas mais utilizados nesse esquema de pulverização eram os benzimidazóis e dicarboximidas (ambos sistêmicos) e fungicidas protetores como o chlorothalonil e dichlofluanid. Testes de sensibilidade a esses fungicidas foram realizados, e os resultados indicaram que $28 \%$ e $15 \%$ dos isolados apresentavam 
insensibilidade aos fungicidas benzimidazóis e dicarboximidas, respectivamente. Também verificaram que $15 \%$ eram resistentes aos benzimidazóis mas sensiveis aos dicarboximidas, $8 \%$ eram sensíveis aos benzimidazóis e resistentes aos dicarboximidas e por fim $48 \%$ apresentavam resistência cruzada a ambos fungicidas. Desses isolados, 3 apresentaram resistência múltipla (a mais de dois fungicidas) a benzimidazóis, dicarboximidas e N-phenilcarbamatos. Esse trabalho demonstra que esquemas de pulverização fixos, baseados quase que exclusivamente em fungicidas sistêmicos específicos, utilizados freqüentemente em cultivos intensivos em casas de vegetação, acarretam o rápido surgimento de resistência não apenas a um tipo de fungicida, mas a vários tipos, podendo trazer sérias conseqüências para o controle efetivo do mofo cinzento.

Cabrini (1985), estudando a sensibilidade de isolados de $B$. cinerea provenientes de regiões produtoras de morango do Estado de São Paulo, Brasil, obteve que de 52 isolados obtidos, 12 apresentaram resistência ao fungicida benomyl. Vale salientar que dos 52 isolados, 23 deles apresentavam histórico de exposição ao fungicida e que nenhum caso de resistência foi verificado nos demais isolados nunca expostos ao fungicida.

Também no Brasil, Ghini (1996) avaliou a sensibilidade de 28 isolados de $B$. cinerea a benomyl, iprodione e propiconazole. Dos 28 isolados, 12 eram provenientes de cultivos em casas de vegetação, principalmente de flores e plantas ornamentais. Apenas 3 isolados podiam ser considerados sensíveis ao fungicida benomyl, considerando-se o valor de $\mathrm{ED}_{50}$ de $70 \mathrm{ppm}$ para o fungicida. Alguns isolados também apresentaram ligeira insensibilidade a iprodione e propiconazole. 


\section{MATERIAL E MÉTODOS}

\subsection{Isolamento}

Isolados do fungo B. cinerea foram obtidos a partir de órgãos reprodutivos (flores e frutos) de diferentes espécies hortícolas, apresentando sintomas típicos de mofo cinzento, provenientes de cultivos comerciais de diferentes regiões dos estados de São Paulo e Minas Gerais.

Amostras de materiais vegetais com sintomas de mofo cinzento, foram colocadas em câmara úmida sob iluminação contínua, fornecida por 3 lâmpadas fluorescentes (Dura Max GE, super luz do dia, 40W, espectro de radiação contínuo entre 305 e $700 \mathrm{~nm}$ ), colocadas a uma altura de $35 \mathrm{~cm}$, e temperatura ao redor de $20^{\circ} \mathrm{C}$. Após 5 dias de incubação, obteve-se intensa esporulação marrom acinzentada do fungo na superficie dos tecidos afetados; com auxilio de agulha esterilizada, conídios do fungo foram transferidos para placas de Petri contendo meio de cultura de BDA ("potato dextrose agar" da MERCK; 39g/L). Essas placas de Petri foram incubadas em câmara ambiente (Bitronette Mark III, Lab-Line Instruments), com temperatura ao redor de $20^{\circ} \mathrm{C}$ e iluminação contínua fornecida por lâmpadas fluorescentes similares às anteriormente citadas. Cinco dias após o isolamento, os fungos apresentaram intenso crescimento micelial $\mathrm{e}$ esporulação por quase toda a placa de Petri. 


\subsection{Preservação dos isolados}

Os isolados de $B$. cinerea obtidos, foram preservados através de repicagens sucessivas, utilizando-se para tal meio de BDA ("potato dextrose agar" da MERCK; 39g/L). Também utilizou-se do método de Castellani, onde discos de meio de BDA mais micélio do fungo foram transferidos para vidros de penicilina com $4 \mathrm{ml}$ de água destilada estéril, sendo posteriormente lacrados e mantidos sob temperatura ao redor de $10^{\circ} \mathrm{C}$. Esse método, descrito por Figueiredo (1967), foi utilizado para manutenção de isolados de $B$. cinerea por Ghini (1984) e Cabrini (1985), permitindo que os isolados mantivessem sua viabilidade e habilidade de esporular, além das características morfológicas, inalteradas.

\subsection{Obtenção de conídios}

Objetivando a caracterização morfológica dos isolados de $B$. cinerea através da medição do comprimento e da largura de conídios, culturas dos isolados do fungo em placas de Petri tipo "Pirex" em meio de BDA ("potato dextrose agar for microbiology MERCK"; 39g/L) foram mantidas sob 2 lâmpadas fluorescentes (Dura Max GE, super luz do dia, 40W, espectro de radiação contínuo entre 305 e $700 \mathrm{~nm}$ ), a $35 \mathrm{~cm}$ acima das placas e iluminação contínua, em biotronete com temperatura ao redor de $20^{\circ} \mathrm{C}$, para produção de conídios. Essa metodologia descrita por Leach (1962), permite a indução de esporulação em fungos que sejam sensíveis a comprimentos de onda próximos do ultravioleta, como é o caso de $B$. cinerea.

Após sete dias de incubação nas condições acima citadas, todos os isolados apresentaram esporulação intensa.

\subsection{Caracterização morfológica}

Após a obtenção de conídios dos isolados de $B$. cinerea, efetuou-se a medição do comprimento e da largura de 50 conídios por isolado. Para tal, utilizou-se de equipamento 
de vídeo (Panasonic Industrial Color CCD Camara) acoplado a microscópio óptico (Olympus CH2) e lâmina graduada (Mikrometer E. Leitz).

O método consistiu em projetar a imagem dos conídios na tela de um monitor de vídeo, e medir diretamente na tela do mesmo o comprimento e largura dos conídios com auxílio de régua milimetrada utilizada em desenho técnico.

Para calibração do equipamento, inicialmente obteve-se um fator de conversão da unidade $\mathrm{mm}$ (medida na tela) para $\mu \mathrm{m}$ (dimensão real dos conídios) projetando-se primeiramente na tela a lâmina graduada (Mikrometer E. Leitz). A lâmina possui gravada em seu corpo pequena régua de $2 \mathrm{~mm}$, subdividida em 200 partes de $0,01 \mathrm{~mm}(10 \mu \mathrm{m})$. Utilizando-se o aumento de 40x (lente EA40; 0,65; 160/0.17) do microscópio óptico, a pequena régua foi projetada na tela do monitor de vídeo e com a régua milimetrada mediu-se $130 \mathrm{~mm}$ da imagem da mesma. A medida de $130 \mathrm{~mm}$ correspondia a 5 divisões da pequena régua ou $50 \mu \mathrm{m}$. Por regra de três simples obteve-se que $1 \mathrm{~cm}$ corresponde a $3,8462 \mu \mathrm{m}$. Assim, a medida de largura ou comprimento dos conídios obtidas em centímetros multiplicada por 3,8462 resultou na dimensão dos mesmos em $\mu \mathrm{m}$.

Esse método proporcionou maior rapidez nas leituras, além de maior facilidade de execução e menor desgaste do operador, quando comparado com o método tradicional de medição de estruturas fúngicas com a utilização de ocular micrométrica (Filar Micrometer Eyepiece, Bausch \& Lomb).

O dimensionamento dos conídios foi efetuado após suspensão dos mesmos em corante lactofenol (cristais de fenol, 20g; ácido lático, 20g; glicerol, 40g; "cotton blue", $1 \mathrm{~g}$ e água destilada, 20ml) e subsequente montagem de lâminas para microscopia óptica (lâmina e lamínula de vidro).

\subsection{Caracterização patogênica}

Para a caracterização patogênica dos isolados de $B$. cinerea efetuou-se a inoculação de discos de folha, frutos ou órgãos florais dos hospedeiros hortícolas de onde obteve-se os isolados de $B$. cinerea. 
O inóculo utilizado consistiu de suspensão de conídios do fungo, na concentração de $10^{6}$ esporos/ml mais Tween $20(0,1 \%)$.

Discos de folha de caquizeiro, em número de quatro (4), com aproximadamente $15 \mathrm{~mm}$ de diâmetro foram inoculados com a suspensão de conídios através da deposição de gota sobre os tecidos foliares, seguindo-se metodologia utilizada por Ghini (1984). Após inoculação os discos foram colocados em condições de câmara úmida e incubados a temperatura ao redor de $20^{\circ} \mathrm{C}$ e fotoperíodo de 14 horas. Os controles foram inoculados apenas com água mais Tween $20(0,1 \%)$.

Os órgãos florais e frutos, foram inoculados através de pulverização da suspensão de conídios, sendo posteriormente colocados em condições de câmara úmida e incubados a temperatura ao redor de $20^{\circ} \mathrm{C}$ e fotoperiodo de 14 horas, segundo metodologia descrita por Hazendonk et al (1995). Os controles foram inoculados apenas com água mais Tween $20(0,1 \%)$, num total de 4 repetições para cada isolado e delineamento totalmente casualizado.

A avaliação foi efetuada 48h após a inoculação, contando-se o número de discos de folha, órgãos florais e frutos com sintomas de mofo cinzento (manchas aquosas marrom e crescimento micelial mais esporulação marrom acinzentada).

\subsection{Avaliação da transmitância de mantas plásticas}

Para avaliação das mantas plásticas, quanto a sua propriedade de bloquear comprimentos de onda próximos do ultravioleta, utilizou-se espectro radiômetro (Licor LI 1800), mensurando-se a transmitância dos materiais testados.

As mantas avaliadas foram o polietileno não aditivado (transparente, Nortene,

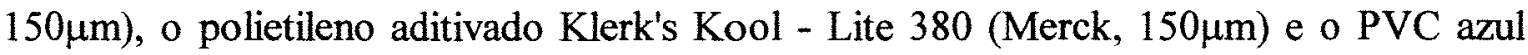
(Sansuy, $150 \mu \mathrm{m}$ ). A manta de polietileno aditivado Klerk's Kool - Lite 380, segundo dados do fabricante, possui característica de bloquear os comprimentos de onda próximos do ultravioleta, podendo desse modo influenciar negativamente na esporulação de alguns fungos. Os fabricantes dos demais materiais não forneceram especificação a esse respeito. 
As leituras no espectroradiômetro foram efetuadas sob luz do sol no período do dia de maior insolação (ao meio dia, com o sol a pino). O sol foi utilizado como fonte luminosa de referência, pois é a fonte de energia da qual todos organismos se utilizam, emitindo todos os comprimentos de onda. Os dados coletados foram processados e plotados com a utilização de microcomputador com o programa de interface LI1800/DOS, que acompanha o equipamento.

\subsection{Avaliação da esporulação "in vitro"}

A fim de avaliar a influência de comprimentos de onda próximos do ultravioleta na esporulação dos isolados de B. cinerea, efetuou-se ensaio de esporulação "in vitro".

Discos de meio de BDA ("potato dextrose agar" da MERCK; 39g/L) mais micélio do fungo com $0,5 \mathrm{~cm}$ de diâmetro, oriundos de colônias com 7 dias de idade, foram transferidos para placas de Petri contendo meio de BDA. Essas placas foram colocadas, recobertas ou não com mantas plásticas, sob 2 lâmpadas fluorescentes (Dura Max GE, super luz do dia, $40 \mathrm{~W}$, espectro de radiação contínuo entre 305 e $700 \mathrm{~nm}$ ), a $35 \mathrm{~cm}$ acima das mesmas, sendo o fotoperíodo de 14 horas, e temperatura ao redor de $20^{\circ} \mathrm{C}$.

Os tratamentos foram: testemunha (sem recobrimento com mantas plástica, mantendo-se as placas sem tampa, expostas diretamente à radiação emitida pelas lâmpadas), polietileno não aditivado (placas recobertas), polietileno aditivado (placas recobertas) e PVC azul (placas recobertas). Foram utilizadas 4 placas por tratamento para cada isolado, com delineamento totalmente casualizado.

Após sete dias de incubação nas condições citadas anteriormente, avaliou-se a produção de conídios. Inicialmente os conídios foram suspensos da colônia com $5 \mathrm{ml}$ de solução $0,1 \%$ de Tween 80 , através de raspagem cuidadosa com auxilio de pincel, para destacar todo micélio aéreo e conidióforos do meio de BDA. Após essa operação a suspensão de conídios obtida, foi filtrada através de camada de gaze e algodão e cuidadosamente transferida para outro frasco, efetuando-se novamente lavagem da placa 
com $5 \mathrm{ml}$ da solução citada, para remoção de conídios remanescentes. A concentração de conídios foi mensurada através de contagem em hemacitômetro.

\subsection{Avaliação da sensibilidade a fungicidas}

Os isolados de $B$. cinerea foram avaliados quanto a sua sensibilidade a fungicidas, visando principalmente detecção de possível existência de resistência a alguns dos compostos testados.

Os testes foram efetuados "in vitro", em placas de Petri contendo meio de BDA ("potato dextrose agar" da MERCK; 39g/L) mais fungicida.

Os fungicidas avaliados foram: benomyl, iprodione, azoxystrobin e difenoconazole (Tabela 1), sendo todos sistêmicos específicos.

Benomyl e iprodione são os fungicidas comumente e intensivamente utilizados em cultivos hortícolas para o controle do mofo cinzento, já difenoconazole e azoxystrobin fungicidas potencialmente interessantes para o controle da doença, mas sem histórico de utilização nos cultivos de onde foram obtidos os isolados.

As concentrações a testadas foram: 0, 0.1, 1, 10,100 e $1000 \mathrm{ppm}$ (mg i.a./l).

Tabela 1. Fungicidas sistêmicos avaliados na inibição do crescimento micelial de isolados de $B$. cinerea

\begin{tabular}{|c|c|c|c|}
\hline Fungicida & Grupo Químico & Modo de Ação & Concentração \\
\hline Azoxystrobin & Estrobirulina & $\begin{array}{l}\text { Inibição da } \\
\text { respiração } \\
\text { mitocondrial }\end{array}$ & $800 \mathrm{~g} / \mathrm{kg}$ \\
\hline Benomyl & Benzimidazóis & $\begin{array}{l}\text { Inibição de mitose } \\
\text { (tubulina) }\end{array}$ & $500 \mathrm{~g} / \mathrm{kg}$ \\
\hline Iprodione & Dicarboximidas & $\begin{array}{l}\text { Processos } \\
\text { oxidativos } \\
\text { (respiração) }\end{array}$ & $500 \mathrm{~g} / \mathrm{kg}$ \\
\hline Difenoconazole & Triazóis & $\begin{array}{c}\text { Inibição de } \\
\text { biossintese de } \\
\text { esteróis } \\
\text { (ergosterol) }\end{array}$ & $250 \mathrm{~g} / 1$ \\
\hline
\end{tabular}

$\mathrm{g}$ de ingrediente ativo por $\mathrm{kg}$ do produto formulado 
A metodologia utilizada foi do fungicida incorporado ao meio de cultura (Nunes, 1992). As diferentes concentrações dos fungicidas foram obtidas através de diluição em série a partir de uma solução estoque, sendo alíquotas destas, adicionadas a frascos do tipo Erlenmeyer contendo meio de BDA ("potato dextrose agar" da MERCK; 39g/L) previamente autoclavado e resfriado a temperatura de $45^{\circ} \mathrm{C}$. Para homogeneização procedeu-se agitação do Erlenmeyer contendo meio de BDA mais o fungicida, efetuando posteriormente a distribuição deste em placas de Petri.

Nas placas de Petri contendo as diferentes concentrações dos fungicidas, transferiu-se disco de meio de $\mathrm{BDA}(0,5 \mathrm{~cm}$ de diâmetro) contendo micélio do fungo oriundo de cultura de 7 dias de idade. As placas foram incubadas em estufa, na ausência total de luz e com temperatura de $20^{\circ} \mathrm{C}$. Para cada tratamento de cada isolado, foram utilizadas 8 repetições, com delineamento totalmente casualizado.

A avaliação foi efetuada através da medição, com auxilio de régua milimetrada, do crescimento radial de colônia, 24 e 48 horas após a montagem do ensaio, determinando-se posteriormente $\mathrm{o} \mathrm{ED}_{50}$ para os fungicidas (concentração necessária para inibir em $50 \% \mathrm{o}$ crescimento micelial dos isolados) 


\section{RESULTADOS}

\subsection{Isolamento}

Dez isolados do fungo $B$. cinerea foram obtidos a partir dos órgãos reprodutivos (flores e frutos) de diferentes espécies hortícolas coletados em produções comerciais dos Estados de São Paulo e Minas Gerais (Tabela 2).

Todos os isolados obtidos, independentemente do hospedeiro e da região de origem apresentaram exposição prévia, de acordo com histórico levantado, a um ou mais fungicidas utilizados no controle químico da doença causada pelo fungo $B$. cinerea.

\subsection{Caracterização morfológica}

O dimensionamento dos conídios dos isolados, através da medida do comprimento e da largura possibilitou enquadrar os 10 isolados dentro da espécie $B$. cinerea, como verifica-se na tabela 3. Os isolados apresentaram comprimento e largura médio de 10,32 e $6,14 \mu$ respectivamente, dentro portanto dos limites para a espécie. 
Tabela 2. Relação dos isolados de Botrytis cinerea avaliados nos experimentos

\begin{tabular}{|c|c|c|c|c|c|}
\hline Isolado & Procedência & Hospedeiro & Histórico & Ano & Observação \\
\hline B1 & Atibaia-SP & $\begin{array}{c}\text { orquídea } \\
\text { (flor) }\end{array}$ & $\begin{array}{l}\text { benomyl } \\
\text { iprodione }\end{array}$ & 1996 & $\begin{array}{c}\text { casa de } \\
\text { vegetação }\end{array}$ \\
\hline B2 & Andradas-MG & $\begin{array}{l}\text { roseira } \\
\text { (flor) }\end{array}$ & $\begin{array}{l}\text { benomyl } \\
\text { iprodione }\end{array}$ & 1996 & $\begin{array}{c}\text { casa de } \\
\text { vegetação }\end{array}$ \\
\hline B3 & Piedade-SP & $\begin{array}{l}\text { caqui } \\
\text { (folha) }\end{array}$ & $\begin{array}{l}\text { benomyl } \\
\text { iprodione }\end{array}$ & 1996 & telado \\
\hline B4 & Atibaia-SP & $\begin{array}{l}\text { roseira } \\
\text { (flor) }\end{array}$ & $\begin{array}{l}\text { benomyl } \\
\text { iprodione }\end{array}$ & 1996 & $\begin{array}{c}\text { casa de } \\
\text { vegetação }\end{array}$ \\
\hline B5 & Atibaia-SP & $\begin{array}{l}\text { roseira } \\
\text { (flor) }\end{array}$ & $\begin{array}{l}\text { benomyl } \\
\text { iprodione }\end{array}$ & 1996 & $\begin{array}{c}\text { casa de } \\
\text { vegetação }\end{array}$ \\
\hline B6 & Andradas-MG & $\begin{array}{l}\text { roseira } \\
\text { (flor) }\end{array}$ & $\begin{array}{l}\text { benomyl } \\
\text { iprodione }\end{array}$ & 1996 & $\begin{array}{c}\text { casa de } \\
\text { vegetação }\end{array}$ \\
\hline B7 & Atibaia-SP & $\begin{array}{c}\text { Eustoma sp. } \\
\quad \text { (flor) }\end{array}$ & $\begin{array}{l}\text { benomyl } \\
\text { iprodione }\end{array}$ & 1996 & $\begin{array}{c}\text { casa de } \\
\text { vegetação }\end{array}$ \\
\hline B8 & Mogi das Cruzes-SP & $\begin{array}{c}\text { maracujá } \\
\text { (fruto) }\end{array}$ & benomyl & 1996 & campo \\
\hline B9 & Atibaia-SP & $\begin{array}{l}\text { roseira } \\
\text { (flor) }\end{array}$ & $\begin{array}{l}\text { benomyl } \\
\text { iprodione }\end{array}$ & 1996 & $\begin{array}{c}\text { casa de } \\
\text { vegetação }\end{array}$ \\
\hline $\mathrm{B} 10$ & Andradas-MG & $\begin{array}{l}\text { roseira } \\
\text { (flor) }\end{array}$ & $\begin{array}{l}\text { benomyl } \\
\text { iprodione }\end{array}$ & 1996 & $\begin{array}{c}\text { casa de } \\
\text { vegetação }\end{array}$ \\
\hline
\end{tabular}


Tabela 3. Análise dos componentes morfológicos dos conídios dos isolados de $B$. cinerea.

\begin{tabular}{lcc}
\hline Isolado de B. cinerea & Comprimento $(\mu \mathrm{m})^{1,2}$ & Largura $(\mu \mathrm{m})^{1,2}$ \\
\hline B1 & $9,80 \mathrm{c}$ & $6,76 \mathrm{ab}$ \\
B2 & $10,05 \mathrm{bc}$ & $6,46 \mathrm{abc}$ \\
B3 & $11,71 \mathrm{a}$ & $6,09 \mathrm{bcd}$ \\
B4 & $10,23 \mathrm{bc}$ & $5,91 \mathrm{~cd}$ \\
B5 & $9,74 \mathrm{c}$ & $5,93 \mathrm{~cd}$ \\
B6 & $10,60 \mathrm{bc}$ & $5,83 \mathrm{de}$ \\
B7 & $9,74 \mathrm{c}$ & $6,65 \mathrm{a}$ \\
B8 & $9,87 \mathrm{c}$ & $5,56 \mathrm{de}$ \\
B9 & $10,97 \mathrm{ab}$ & $5,32 \mathrm{e}$ \\
B10 & $10,54 \mathrm{bc}$ & $6,98 \mathrm{~cd}$ \\
\hline Média & 10,32 & 6,14 \\
CV & 14,08996 & 14,61504 \\
Pr>F & 0,0001 & 0,0001 \\
\hline
\end{tabular}

${ }^{1}$ Médias seguidas de mesma letra, na coluna, não diferem entre si ao nível de significância $5 \%$ (Tukey).

${ }^{2}$ Média de 50 observações.

Apesar das médias do comprimento e da largura enquadrarem os 10 isolados numa mesma espécie, foram constatadas diferenças significativas entre eles (tabela 3), o que permitiu, através da análise de "cluster" (Morgan, 1971), apresentada na figura 1, aproximar morfologicamente isolados distintos, tanto no sentido de hospedeiro como da região de onde foi obtido.

Os isolados com maior semelhança são aqueles obtidos num mesmo local mas de espécies vegetais totalmente distintas, sendo eles B1 e B7. Esses mesmos isolados aproximam-se muito também do isolado B2, obtido de outro local e de hospedeiro também distinto, aproximando-se este ao isolado B10. Este último por sua vez aproximase dos grupos B6 x B4 e B8 x B5. Os isolados com menor semelhança são B9 e B3. 


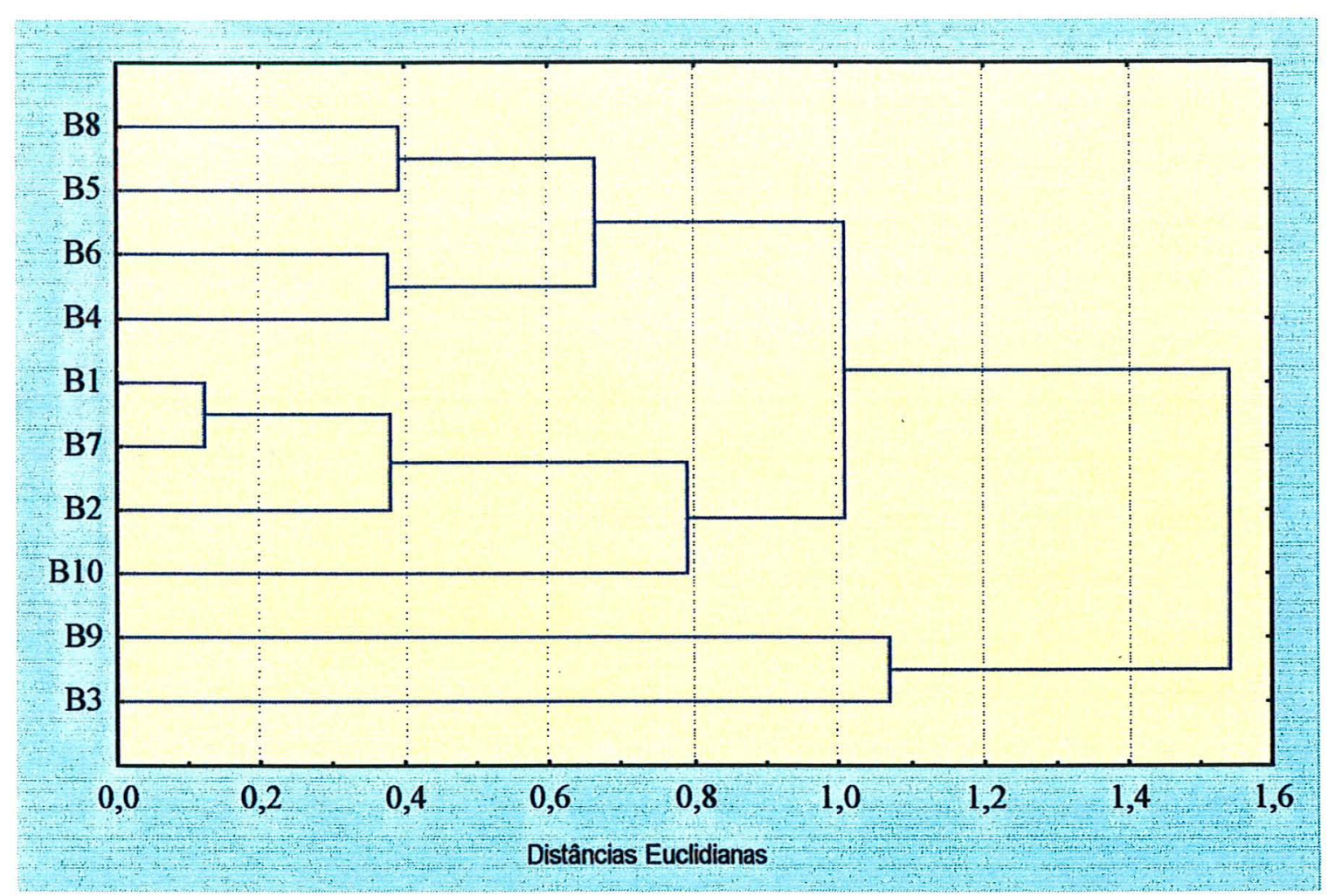

Figura 1. Dendrograma mostrando a similaridade morfológica entre os isolados de $B$. cinerea através da análise de "cluster" (método UPGA, distâncias Euclidianas).

\subsection{Caracterização patogênica}

A inoculação de folhas, flores e frutos com os 10 isolados de B. cinerea proporcionou a verificação da não especificidade do patógeno quanto ao hospedeiro, ou seja, todos os isolados, independente de sua origem, são capazes de infectar tecidos de hospedeiros variados, como pode ser visto na tabela 4 .

Não ocorreu diferença entre as inoculações dos diferentes isolados nos hospedeiros avaliados, sendo a manifestação de sintomas igual para todos os isolados 48 horas após inoculação (100\% do material inoculado apresentou sintoma). 
Tabela 4. Manifestação de sintomas em diferentes hospedeiros, quando inoculados com os isolados de $B$. cinerea.

\begin{tabular}{|c|c|c|c|c|c|c|c|c|c|c|}
\hline \multirow[b]{2}{*}{ Isolado } & \multicolumn{10}{|c|}{ Hospedeiro $^{1}$} \\
\hline & $\begin{array}{c}\text { Orquídea } \\
(\mathrm{B} 1)^{2}\end{array}$ & $\begin{array}{l}\text { Rosa } \\
(\mathrm{B} 2)^{2}\end{array}$ & $\begin{array}{l}\text { Caqui } \\
\text { (B3) }^{2}\end{array}$ & $\begin{array}{l}\text { Rosa } \\
(\mathrm{B} 4)^{2}\end{array}$ & $\begin{array}{l}\text { Rosa } \\
\text { (B5) }^{2}\end{array}$ & $\begin{array}{l}\text { Rosa } \\
(\mathrm{B} 6)^{2}\end{array}$ & $\begin{array}{c}\text { Lisianthus } \\
(\text { (B7) })^{2}\end{array}$ & $\begin{array}{c}\text { Maracujá } \\
(\mathrm{B} 8)^{2}\end{array}$ & $\begin{array}{l}\text { Rosa } \\
\text { (B9) }^{2}\end{array}$ & $\begin{array}{c}\text { Rosa } \\
(\mathrm{B} 10)^{2}\end{array}$ \\
\hline $\mathrm{B} 1$ & + & + & + & + & + & + & + & + & + & + \\
\hline $\mathrm{B} 2$ & + & + & + & + & + & + & + & + & + & + \\
\hline B3 & + & + & + & + & + & + & + & + & + & + \\
\hline B4 & + & + & + & + & + & + & + & + & + & + \\
\hline B5 & + & + & + & + & + & + & + & + & + & + \\
\hline B6 & + & + & + & + & + & + & + & + & + & + \\
\hline B7 & + & + & + & + & + & + & + & + & + & + \\
\hline B8 & + & + & + & + & + & + & + & + & + & + \\
\hline B9 & + & + & + & + & + & + & + & + & + & + \\
\hline $\mathrm{B} 10$ & + & + & + & + & + & + & + & + & + & + \\
\hline
\end{tabular}

${ }^{\mathrm{T}} 4$ repetições avaliadas, com $100 \%$ das mesmas apresentando sintomas.

${ }^{2}$ Isolado original.

Assim confirma-se ser B. cinerea, um patógeno inespecífico, sendo populações oriundas de regiões e hospedeiros distintos capazes de infectar outros igualmente susceptiveis.

\subsection{Avaliação da transmitância de mantas plásticas}

Os resultados da avaliação da transmitância das mantas plásticas testadas, obtidos através de leitura com espectroradiômetro (Licor LI 1800), podem ser visualizados na figura 2. 


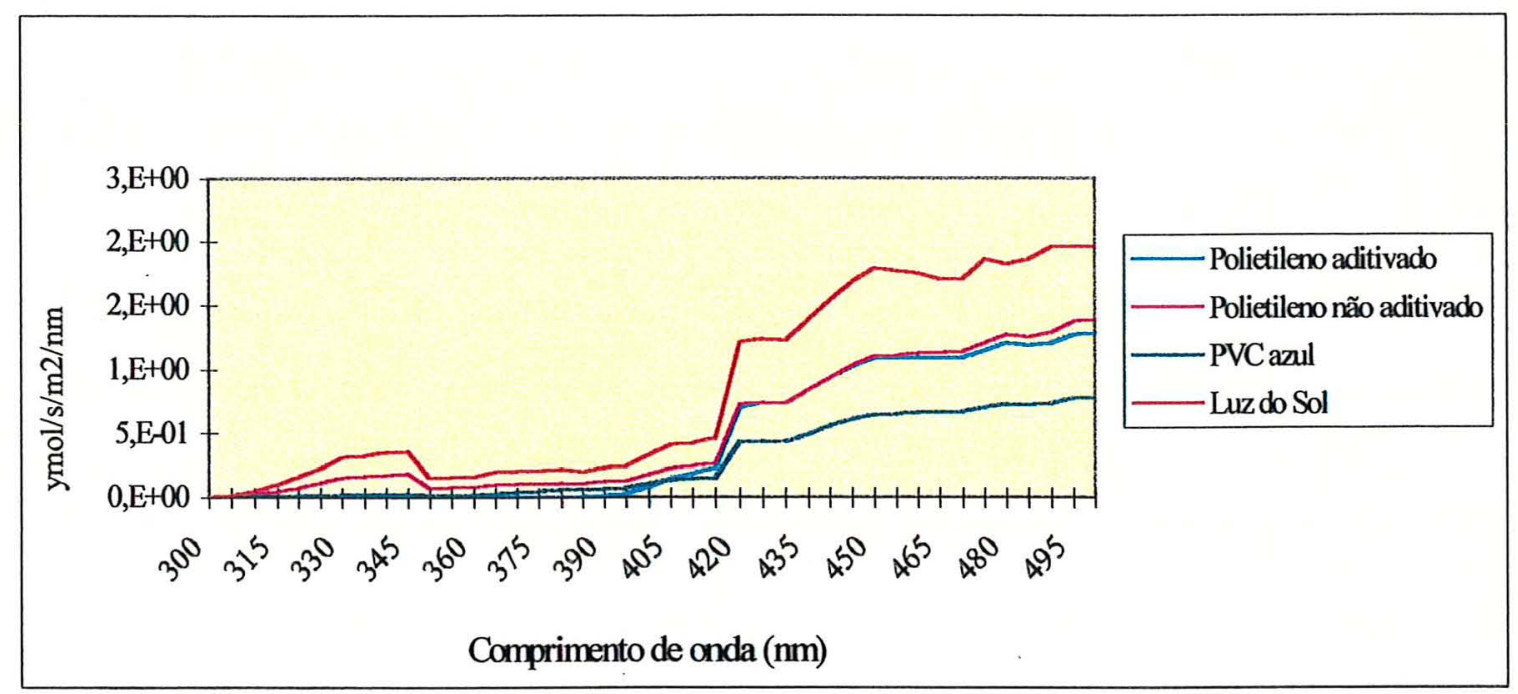

Figura 2. Transmitância da luz na faixa próxima ao ultravioleta e na faixa visível para as três mantas plásticas avaliadas.

Com base na figura 2, pode-se observar que todas as mantas avaliadas diminuem sensivelmente a quantidade de luz incidente. Do ponto de vista qualitativo, a redução da incidência de certos comprimentos de onda por parte das mantas é considerável. A manta de polietileno aditivado, reduz, ou melhor, bloqueia praticamente todos os comprimentos de onda próximos do ultravioleta (faixa entre 200 e $400 \mathrm{~nm}$ ), o mesmo ocorrendo para a manta PVC azul, esta porém numa intensidade pouco menor. Já a manta de polietileno não aditivado não bloqueia a passagem desses comprimentos de onda.

\subsection{Avaliação da esporulação "in vitro"}

Analisando-se graficamente os resultados, apresentados na figura 3, observa-se a ausência de esporulação dos isolados, com exceção do isolado B7, nos tratamentos polietileno aditivado e PVC azul, mostrando claramente que os isolados do fungo $B$. cinerea necessitam de comprimentos de onda próximos do ultravioleta para a esporogênese. No tratamento polietileno comum, observou-se esporulação para todos os isolados, apesar de visivelmente inferior à testemunha, evidenciando aí que esse material 
não tem como propriedade o total bloqueio dos comprimentos de onda próximos ao ultravioleta. Com relação ao isolado $\mathrm{B} 7$, o único a apresentar esporulação em todos os tratamentos, pode-se dizer que se trata de fato passível de acontecimento nessa espécie de fungo, que pode também apresentar alguma esporulação quando mantido em ausência de luz, fato este observado para o isolado durante seu cultivo e manutenção em condições controladas no escuro.

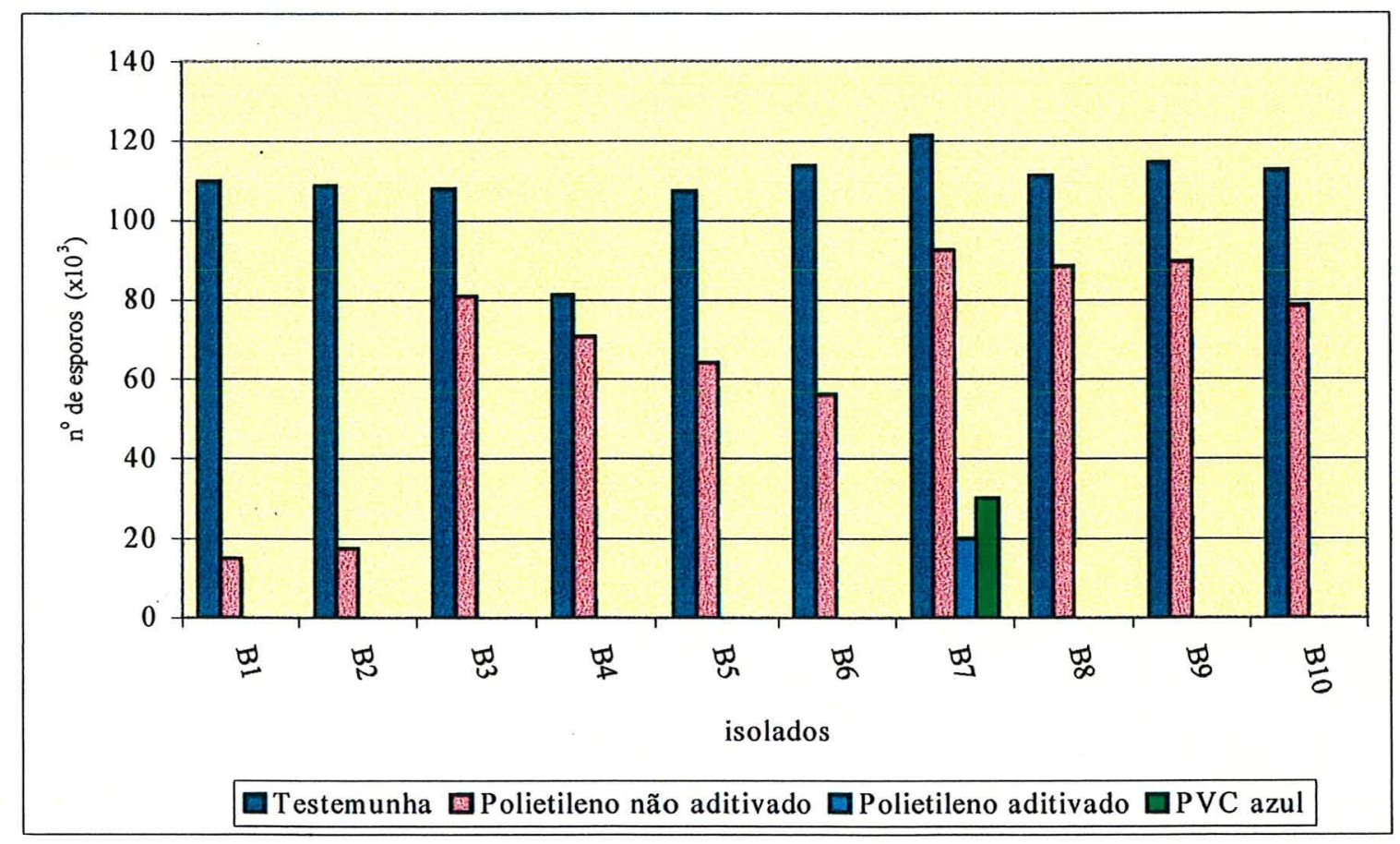

Figura 3. Avaliação da esporulação "in vitro" dos isolados de $B$. cinerea sob diferentes mantas plásticas.

Os resultados obtidos neste ensaio também confirmam os resultados obtidos na avaliação da transmitância das mantas plásticas utilizadas (item 4.4.), mostrando que as mantas de polietileno aditivado e de PVC azul são eficientes em bloquear os comprimentos de onda próximos do ultravioleta, necessários para a esporulação de $B$. cinerea. 


\subsection{Avaliação da sensibilidade a fungicidas}

Os isolados de B. cinerea obtidos, foram avaliados quanto a sua sensibilidade "in vitro" aos fungicidas benomyl, iprodione, difenoconazole e azoxystrobin, sendo os resultados apresentados graficamente nas figuras 4 a 11 .

Analisando-se os resultados obtidos nas figuras 4 e 5, nota-se que o fungicida benomyl praticamente não inibiu nenhum dos isolados até a concentração de $100 \mathrm{ppm}$, sendo a concentração de 1000 ppm inibitória apenas para os isolados B4, B1, B8, B2 e B7, sendo esse resultado observado logo na primeira avaliação (24 horas após a inoculação do meio de BDA com o fungicida).

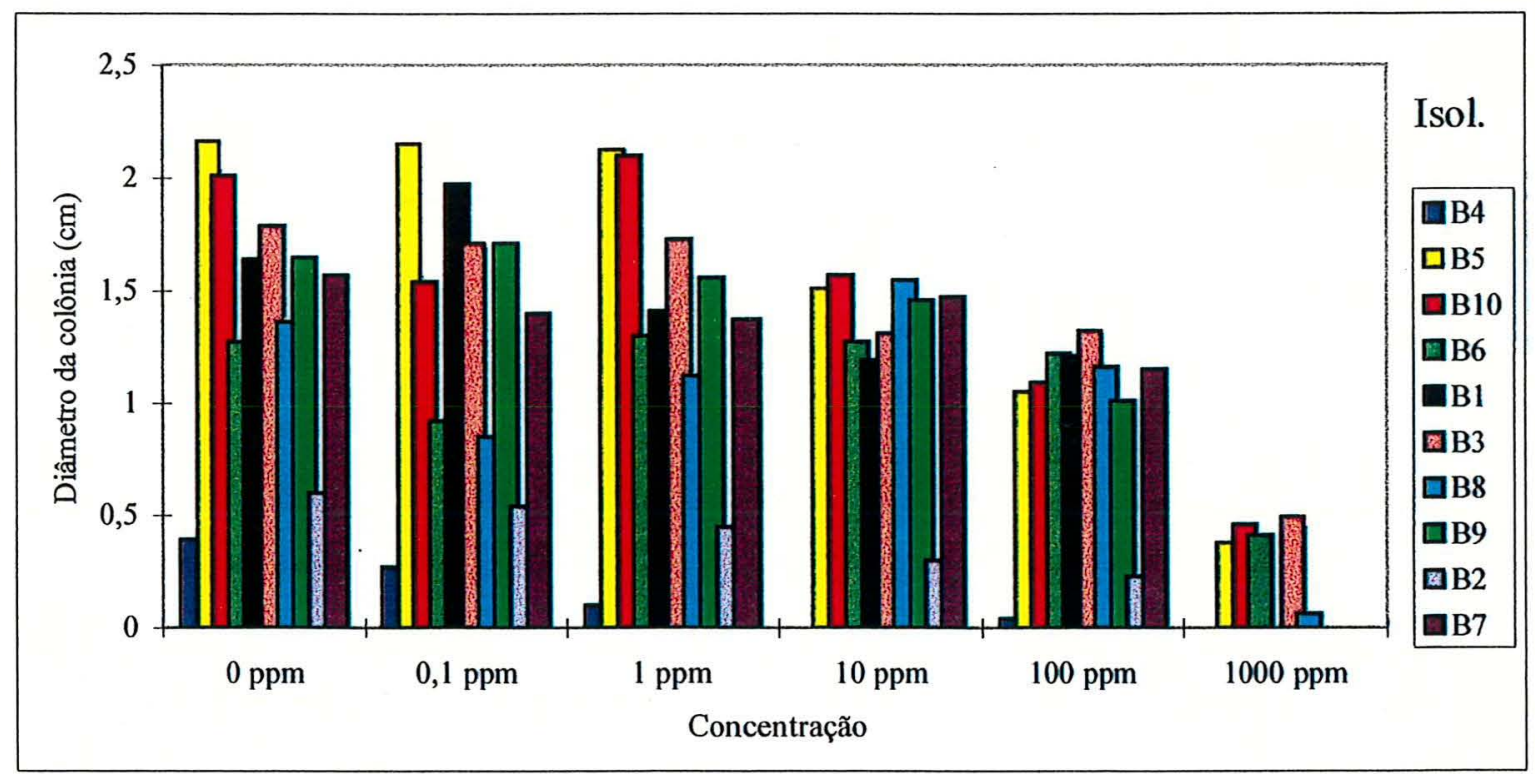

Figura 4. Sensibilidade dos isolados (Isol.) de B. cinerea ao fungicida benomyl (24 horas após a inoculação do meio de BDA com fungicida).

Também nota-se o decrescente crescimento micelial, expresso em diâmetro de colônia, do fungo $B$. cinerea quanto maior a concentração do fungicida benomyl ao qual o 
mesmo foi exposto, ou seja, apesar de existir crescimento, este mostra-se menor quanto maior a concentração do fungicida benomyl.

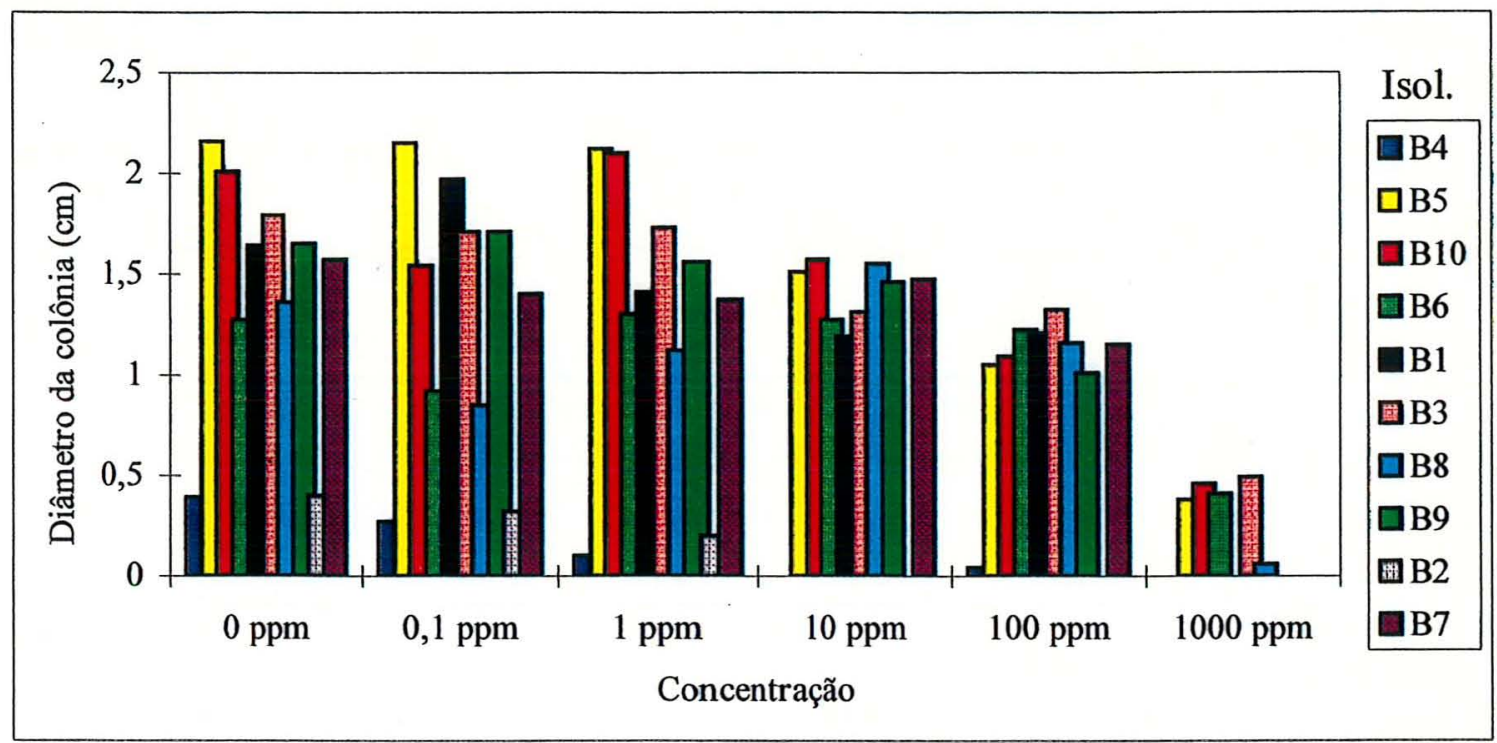

Figura 5. Sensibilidade dos isolados (Isol.) de B. cinerea ao fungicida benomyl (48 horas após inoculação do meio de BDA com fungicida).

Para o fungicida iprodione, pode-se observar na figura 6 que, após 24 horas de incubação a maioria dos isolados não apresentou crescimento micelial já a partir de 1 ppm, sendo $10 \mathrm{ppm}$ limitante para os isolados, exceto para o isolado B4. Na segunda avaliação (48 horas de incubação) esse mesmo isolado, como observa-se na figura 7, apresentou crescimento também na concentração de 100 ppm, existindo também algum crescimento em 10 ppm para os isolados B5 e B7, sendo para os demais a concentração limite $1 \mathrm{ppm}$.

Também nota-se para o fungicida iprodione, o decréscimo no crescimento micelial dos isolados quanto maior a concentração do fungicida, estando o limite para o crescimento entre as concentrações 1 e $10 \mathrm{ppm}$ para a maioria dos isolados avaliados.

Em comparação com o fungicida benomyl, os isolados de $B$. cinerea mostram-se mais sensiveis ao fungicida iprodione do que ao mesmo. 


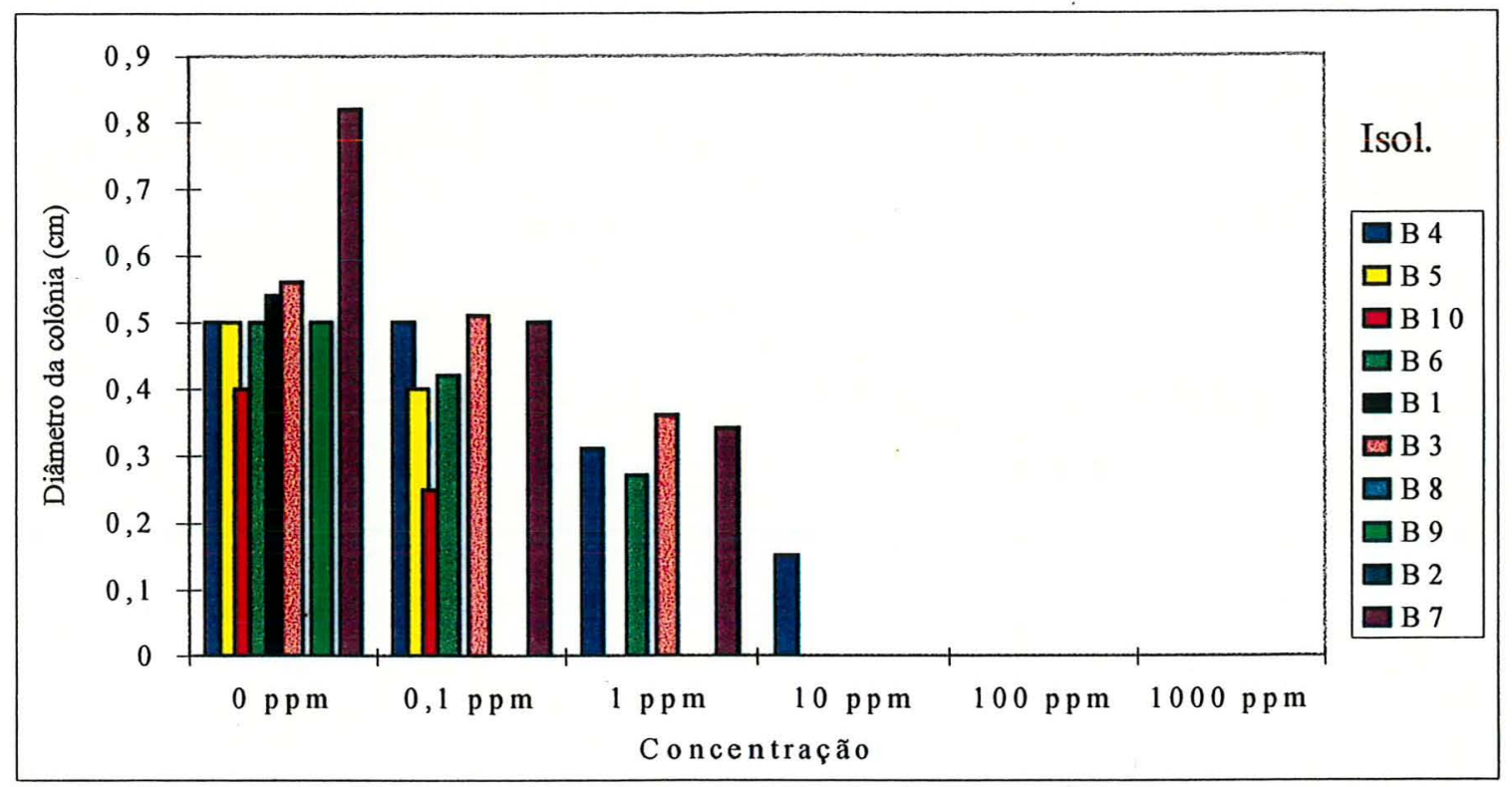

Figura 6. Sensibilidade dos isolados (Isol.) de B. cinerea ao fungicida iprodione (24 horas após inoculação do meio de BDA com fungicida).

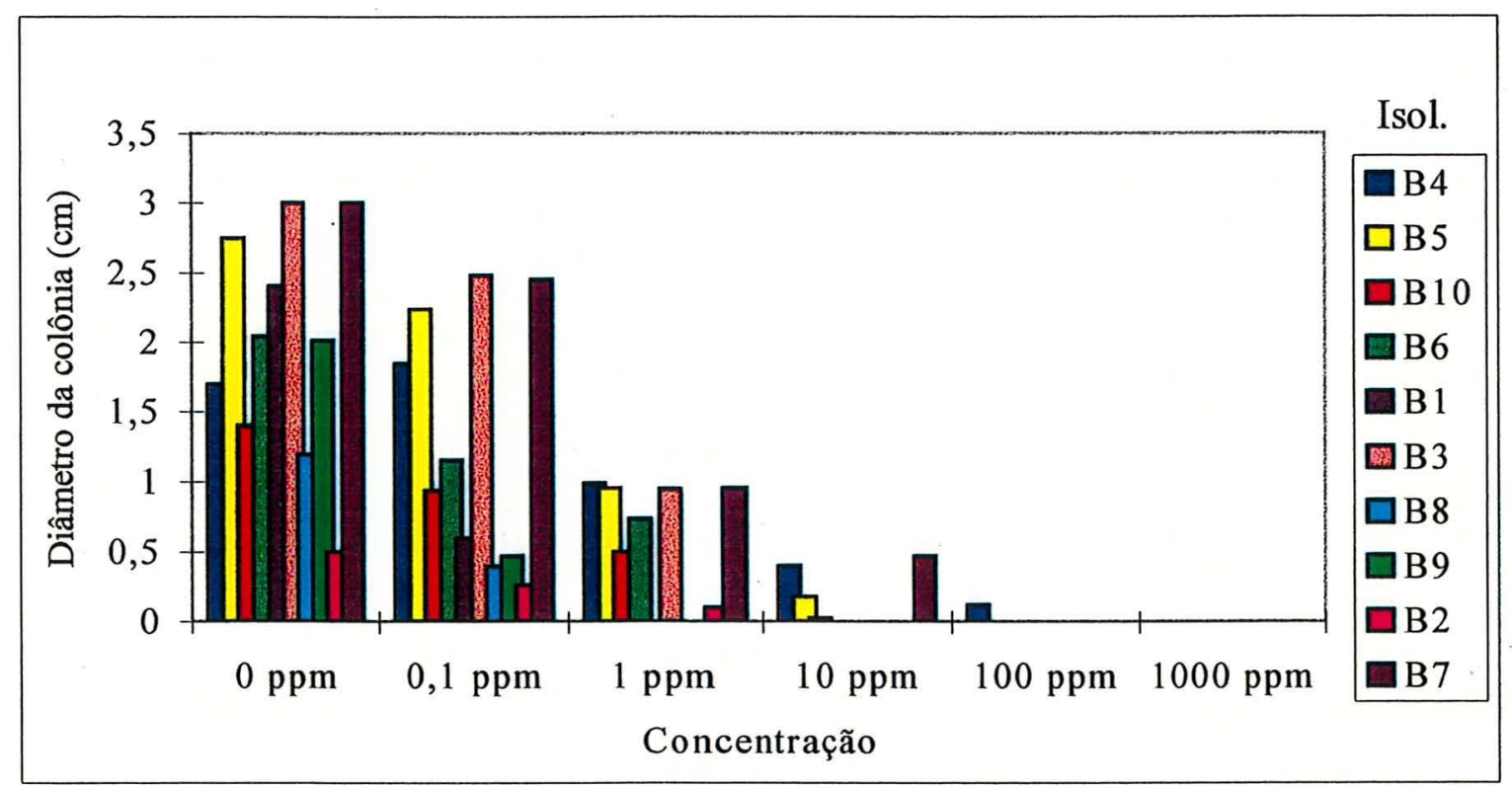

Figura 7. Sensibilidade dos isolados (Isol.) de $B$. cinerea ao fungicida Iprodione (48 horas após inoculação do meio de BDA com fungicida). 
No caso do fungicida difenoconazole, observa-se nas figura 8 e 9 que o limite para o crescimento micelial situa-se entre as concentrações 0,1 e $1 \mathrm{ppm}$ para a maioria os isolados, sendo esse fato notado com maior clareza na figura 9. Apenas os isolados B10 e B1 apresentaram crescimento micelial (expresso em diâmetro de colônia) nas concentrações 10 e 100 ppm, e em 1000 ppm apenas o isolado B1 conseguiu certo desenvolvimento.

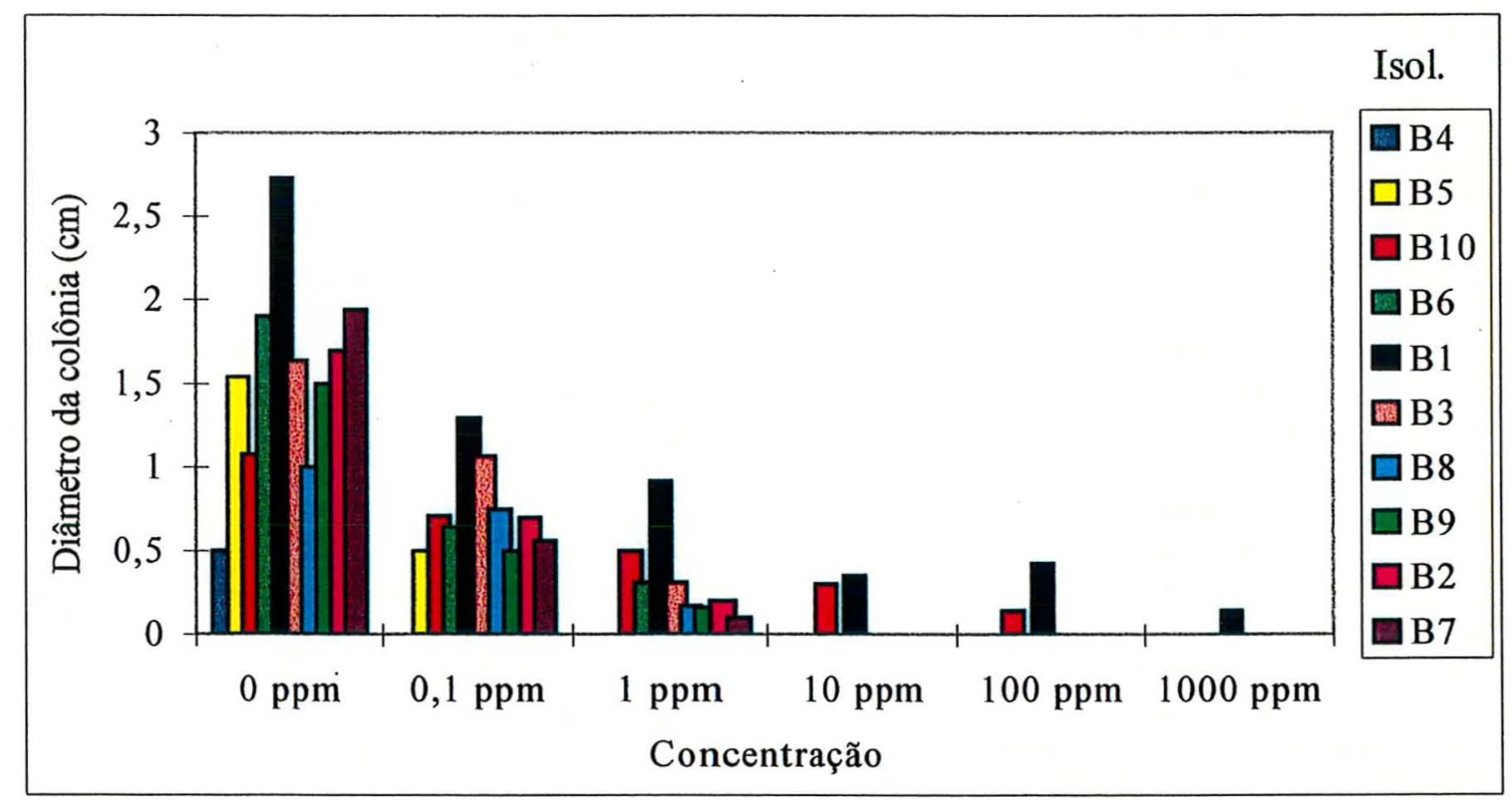

Figura 8. Sensibilidade dos isolados (Isol.) de B. cinerea ao fungicida difenoconazole (24 horas após inoculação do meio de BDA com fungicida). 


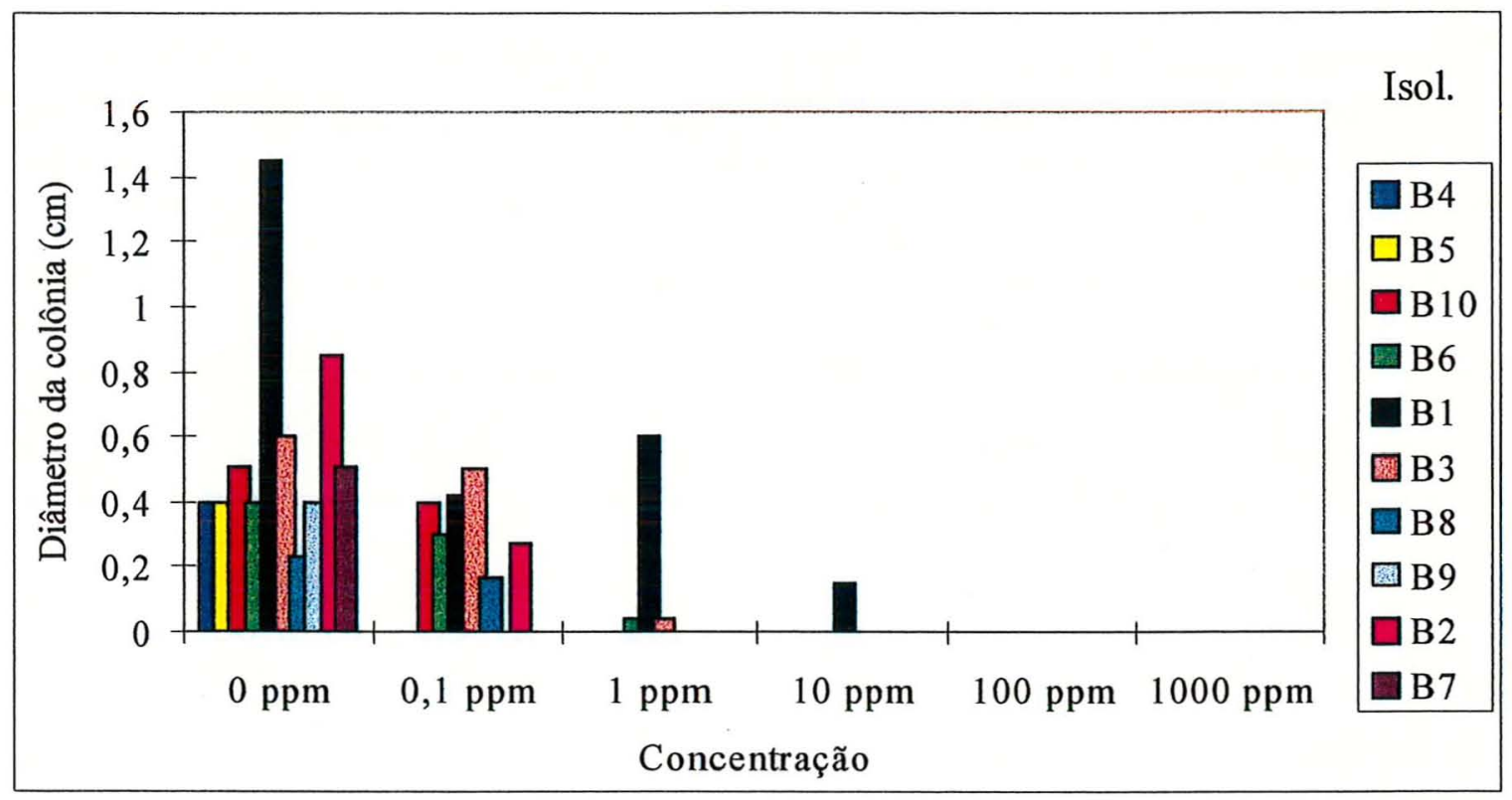

Figura 9. Sensibilidade dos isolados (Isol.) de B. cinerea ao fungicida difenoconazole (48 horas após inoculação do meio de BDA com fungicida).

Avaliando-se a sensibilidade dos isolados ao fungicida azoxystrobin, ao qual os mesmos nunca foram expostos, nota-se nas figuras 10 e 11, que ocorre grande variação entre os isolados. Na figura 10, referente a primeira avaliação (24 horas), observa-se grande crescimento até a concentração de 100 ppm para os isolados B4, B10, B1, B3 e B7, e em 1000 ppm presente crescimento dos isolados B10, B3 e B7. Para os demais não ocorreu crescimento já a partir de 0,1 ppm. 


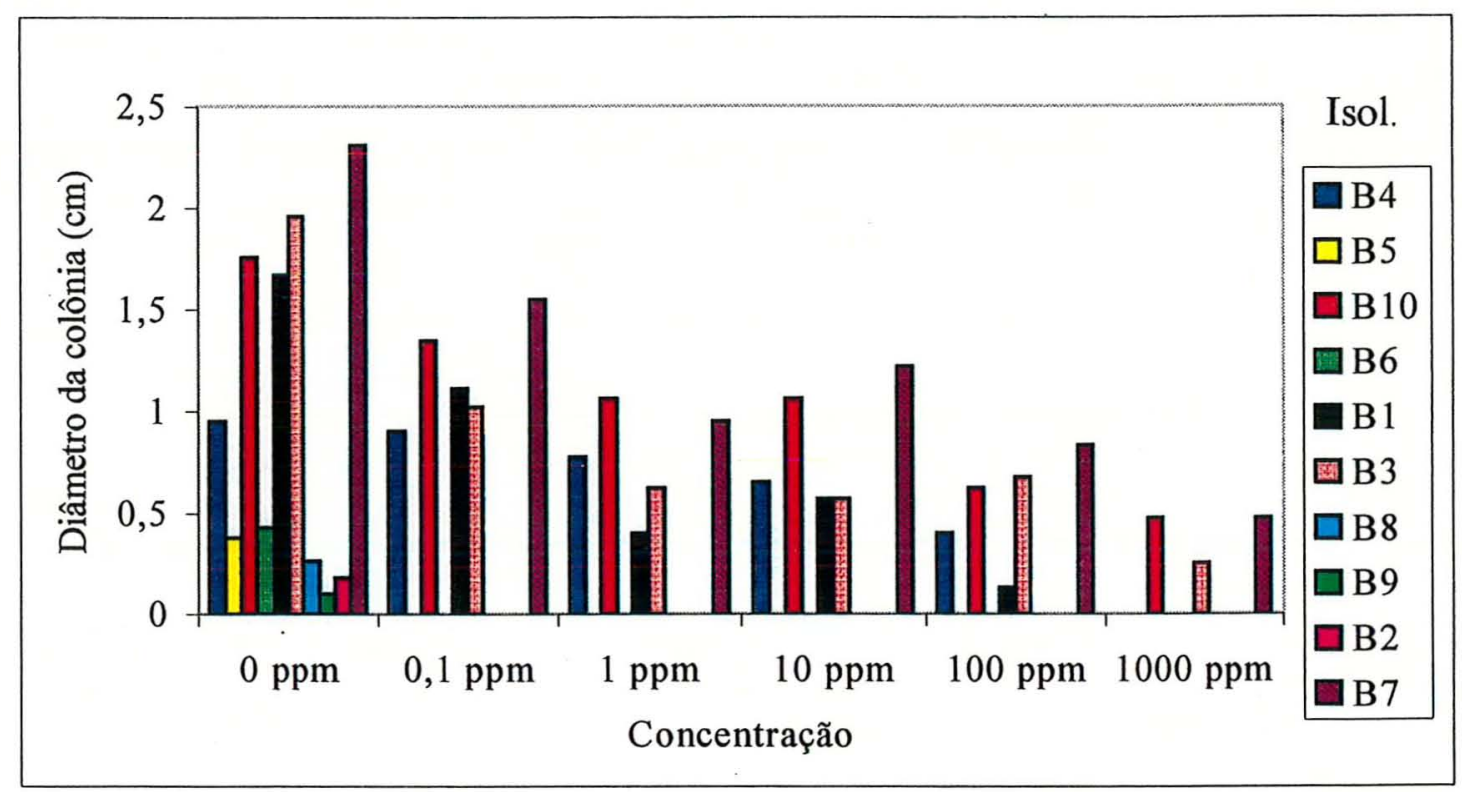

Figura 10. Sensibilidade dos isolados (Isol.) de B. cinerea ao fungicida azoxystrobin (24h após inoculação do meio de BDA com fungicida).

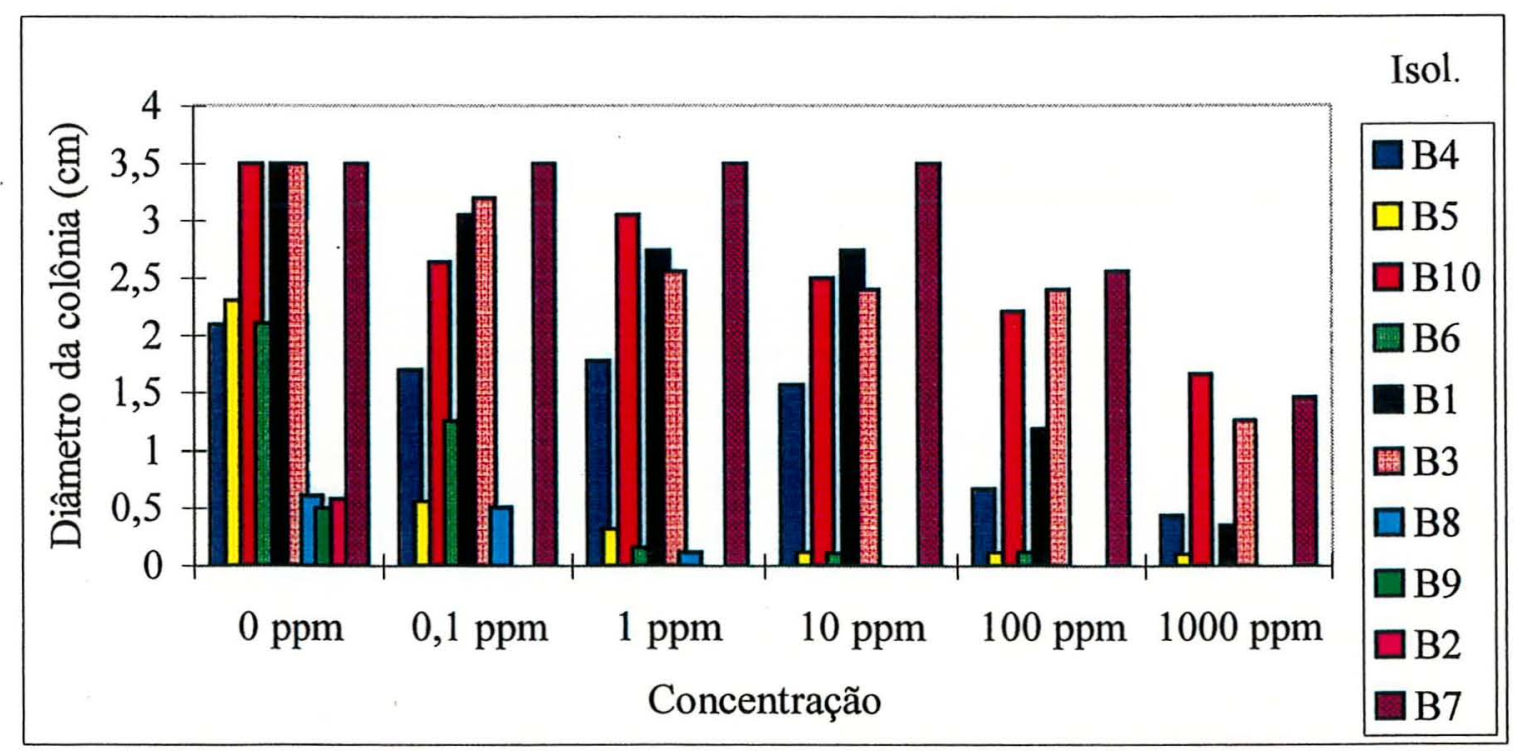

Figura 11. Sensibilidade dos isolados (Isol.) de B. cinerea ao fungicida azoxystrobin ( $48 \mathrm{~h}$ após inoculação do meio de BDA com fungicida). 
$\mathrm{Na}$ segunda avaliação, como observa-se na figura 11, a concentração de $0,1 \mathrm{ppm}$ do fungicida foi limitante para os isolados B9 e B2, os quais não apresentaram nenhum crescimento. Para o isolado B8 a concentração limite foi 1 ppm, não ocorrendo crescimento em maiores concentrações.

Já o isolado B6 cresceu até a concentração de $100 \mathrm{ppm}$, tendo o crescimento para os demais isolados ocorrido até a última concentração avaliada (1000 ppm do fungicida).

$\mathrm{Na}$ tabela 5, são apresentados os resultados da determinação do $\mathrm{ED}_{50}$ dos fungicidas testados para todos os isolados avaliados, baseando-se na análise gráfica das figuras 4 a 11 , baseando-se no crescimento dos isolados nas diferentes concentrações dos fungicidas em relação à testemunha.

Tabela 5. ED $\mathrm{E}_{50}$ dos fungicidas avaliados para a inibição do crescimento micelial "in vitro" dos isolados de $B$. cinerea.

$\mathrm{ED}_{50}$ dos fungicidas $(\mathrm{ppm})^{1,2}$

\begin{tabular}{lcccc} 
Isolado & Benomyl & Iprodione & Difenoconazole & Azoxystrobin \\
\hline B1 & 100 & 0,1 & $0,1-1$ & 100 \\
B2 & 100 & $0,1-1$ & 0,1 & $<0,1$ \\
B3 & $100-1000$ & 1 & $0,1-1$ & $100-1000$ \\
B4 & $0,1-1$ & $1-10$ & $<0,1$ & $10-100$ \\
B5 & $100-1000$ & $1-10$ & $<0,1$ & $<0,1$ \\
B6 & 1000 & 1 & 0,1 & $0,1-11$ \\
B7 & 100 & 1 & $<0,1$ & 1000 \\
B8 & $100-1000$ & 0,1 & $0,1-1$ & $0,1-1$ \\
B9 & 100 & $<0,1$ & $<0,1$ & $<0,1$ \\
B10 & $100-1000$ & $1-10$ & $1-10$ & 1000
\end{tabular}

\footnotetext{
${ }^{1}$ Avaliação das colônias 48 horas após inoculação do meio de BDA com fungicida.

${ }^{2}$ Os valores apresentados são baseados na avaliação gráfica dos resultados dos testes de sensibilidade.
} 
Observando-se na tabela 5 os valores de $\mathrm{ED}_{50}$ para o fungicida benomyl, nota-se que todos os isolados, menos o isolado $\mathrm{B} 4$, apresentam altos valores, situando-se o $\mathrm{ED}_{50}$ para esse fungicida entre 100 e 1000 ppm, mostrando a baixíssima eficiência "in vitro" do produto na inibição do crescimento micelial dos isolados. Numa escala de sensibilidade dos isolados pode-se dizer que o isolado B4 é o mais sensível a benomyl, seguindo-se num patamar intermediário os isolados B1, B9, B2 e B7, e entre os menos sensíveis os isolados $\mathrm{B} 5, \mathrm{~B} 10, \mathrm{~B} 3, \mathrm{~B} 8$ e finalmente o isolado $\mathrm{B} 6$ que apresentou o maior $\mathrm{ED}_{50}(1000 \mathrm{ppm})$.

Para o fungicida iprodione, pode-se observar (tabela 5), que os valores de $\mathrm{ED}_{50}$ são menores que os obtidos para benomyl, situando-se para a maioria dos isolados entre 0,1 e 1 ppm, mostrando que os mesmos são mais sensíveis "in vitro" a esse fungicida. $\mathrm{Na}$ escala de sensibilidade podemos colocar entre os mais sensiveis os isolados B9, B8, B1, $\mathrm{B} 2$, entre os intermediários os isolados B6, B3 e B7, e entre os menos sensíveis os isolados B4, B5 e B10.

Resultado similar foi encontrado para o fungicida difenoconazole, onde a maioria dos isolados apresentou $\mathrm{ED}_{50}$ entre 0,1 e 1 ppm ou menos, mostrando grande eficiência "in vitro" desse fungicida na inibição do crescimento micelial de $B$. cinerea. $\mathrm{Na}$ escala de sensibilidade os mais sensiveis são os isolados B4, B5, B9 e B7, seguidos dos isolados B6, $\mathrm{B} 2, \mathrm{~B} 1, \mathrm{~B} 3 \mathrm{e} \mathrm{B} 8 \mathrm{e}$ finalmente o isolado B10.

Já para o fungicida azoxystrobin nota-se grande variação no $\mathrm{ED}_{50}$, sendo alguns isolados inibidos em valores menores que $0,1 \mathrm{ppm}$, caso do isolado $\mathrm{B} 5$, e outros apenas em 1000 ppm, como o isolado B7. Na escala de sensibilidade os isolados B5, B9 e B2 são os mais sensíveis, seguindo-se os isolados B6, B8, B4, B1, B3 e finalmente os isolados B10 e B7.

Ainda na tabela 5, verifica-se que alguns isolados apresentam altos valores de $\mathrm{ED}_{50}$ para todos os fungicidas avaliados, como o isolado $\mathrm{B} 10$, que apresenta para benomyl ED $\mathrm{ED}_{50}$ entre 100 e $1000 \mathrm{ppm}$, para iprodione e difenoconazole entre 1 e $10 \mathrm{ppm}$, e para azoxystrobin $1000 \mathrm{ppm}$. 


\section{DISCUSSÃO}

\subsection{Caracterização morfológica}

A determinação do comprimento e largura dos conídios dos isolados de Botrytis através de medição direta, como a efetuada por Ghini (1984), aliada a utilização de equipamento eletrônico de filmagem, proporcionou a caracterização de isolados do fungo ao nível específico, de maneira rápida e precisa. Portanto a análise morfológica de conídios de Botrytis através do método descrito consiste em ferramenta simples e rápida para diferenciação entre espécies desse fungo.

Apesar dessa simplicidade e rapidez, a caracterização morfológica sozinha, como qualquer método de identificação, pode não garantir isenção de erros, pois, como Ghini (1984) cita em seu trabalho, pode existir grande variabilidade dentro da espécie , como também a ocorrência de heterocárions e semelhança entre espécies, principalmente entre B. cinerea e $B$. alli.

Todos os isolados obtidos enquadraram-se dentro da espécie $B$. cinerea, pois o comprimento e a largura média dos mesmos situou-se dentro dos limites definido pela espécie. Na média os isolados em questão apresentaram comprimento médio de $10,32 \mu \mathrm{m}$ e largura média de $6,14 \mu \mathrm{m}$, situando-se dentro das dimensões médias para essa espécie que são para largura entre 6 e $10 \mu \mathrm{m}$ e para comprimento entre 9 e $14 \mu \mathrm{m}$, de acordo portanto com Hancock \& Lorberr (1963), Morgan (1971), Ghini (1984), Bullit \& Dubos (1988), Crowe et al. (1994) e Daughtrey et al. (1995).

Mas apesar do enquadramento de todos os isolados avaliados dentro de uma mesma espécie, a análise de variância do comprimento e da largura (tabela 3) permitiu que 
fossem detectadas pequenas diferenças significativas entre os mesmos. Essas diferenças poderiam ser usadas para detectar algum tipo de especialização (hospedeiro preferencial) ou agrupamento dentro dessas populações avaliadas, ou então seriam apenas aquelas variações que podem ocorrer dentro de uma espécie, como observado por Ghini (1984).

Apesar dessa possibilidade a análise de "cluster" (figura 1), que ilustra claramente a proximidade entre isolados de acordo com suas características morfológicas (comprimento e largura juntas), permitiu observar que isolados oriundos de hospedeiros de espécies vegetais diferentes mas obtidos de um mesmo local foram os que maior similaridade apresentaram e que isolados obtidos de regiões e hospedeiro totalmente distintos foram os que apresentaram as menores similaridades.

Essa observação permite dizer que num mesmo local existe o predomínio de populações do patógeno mais adaptadas e que são morfologicamente semelhantes, ou então que seja apenas uma população, sendo nesse caso a mais apta e a constituída por membros com pequenas variações morfológicas mas que na média enquadram-se dentro dos padrões morfológicos da espécie $B$. cinerea.

\subsection{Caracterização patogênica}

Detectadas pequenas diferenças morfológicas entre os isolados e supondo-se que essas diferenças possibilitariam a separação ou agrupamento de certas populações, a caracterização patogênica veio a determinar a não existência desse tipo de subdivisão para B. cinerea, pois as inoculações mostraram que todos os isolados são patogênicos a todos os hospedeiros avaliados (tabela 4).

Esse resultado obtido vem a confirmar o já visto anteriormente por Jarvis (1980) que cita mais de 200 hospedeiros de B. cinerea. Assim pode-se dizer, que a patogenicidade de populações de uma mesma espécie, nesse caso B. cinerea (um patógeno não específico e necrotrófico), não constitui critério determinante de especificidade a certos hospedeiros e que conídios oriundos de outros locais qualquer que 
seja seu meio de transporte, ao encontrar um hospedeiro diferente, mas também susceptível e ocorrendo condições favoráveis, podem causar doença.

\subsection{Avaliação da transmitância de mantas plásticas e da esporulação "in vitro"}

As mantas plásticas de polietileno aditivado e de PVC azul, avaliadas como o efetuado por Honda et al. (1977) e Nicot et al. (1996) em seus experimentos com outros materiais fotoseletivos, não permitem a passagem de comprimentos de onda próximos do ultravioleta, ou seja regulam qualitativamente a luz incidente numa casa de vegetação que porventura se utilize dessas mantas como cobertura. Já a manta de polietileno comum, como foi dito, diminui apenas a quantidade de luz incidente.

Do ponto de vista fitopatológico é sabido que $B$. cinerea é estimulado a esporular ou tem essa fase favorecida por comprimentos de onda próximos do ultravioleta (Clark \& Lorbeer, 1973; Colhoun, 1973; Hite, 1973; Honda, 1977). Sendo assim verificou-se no ensaio de esporulação in vitro que realmente as mantas de polietileno aditivado e de PVC azul, por não proporcionarem a passagem do espectro adequado de luz necessário para a esporogênese de $B$. cinerea, inibiu totalmente a esporulação da maioria dos isolados.

O mesmo fato não ocorreu com a manta de polietileno não aditivado, que pouco filtra os comprimentos de onda próximos do ultravioleta, possibilitando portanto esporulação do patógeno.

Com essa informação e sabendo-se que existem mantas plásticas que bloqueiam comprimentos de onda importantes para alguns fungos fitopatogênicos, pode-se em concordância com os trabalhos de Honda et al. (1977), Sasaki et al. (1985), Vakalounakis (1992) e Nicot et al. (1996), utilizar mais essa ferramenta na estratégia de controle de doenças em casas de vegetação, como acontece em algumas regiões produtoras da Colômbia, onde a densidade de conídios de $B$. cinerea no ar no interior é claramente diminuída pela uso do plástico fotoseletivo (Ramírez \& Torres, 1995). 


\subsection{Avaliação da sensibilidade a fungicidas}

Nas décadas recentes várias pragas e patógenos animais e vegetais, tem apresentado resistência a produtos químicos destinados ao seu controle, pelo mundo todo. No caso de fungos fitopatogênicos, com $\mathrm{o}$ advento de fungicidas específicos, o surgimento de populações resistentes a fungicidas tem ocorrido com maior freqüência, principalmente em cultivos intensivos, onde a carga de defensivos utilizada é muito grande. Este fato tem colocado os produtores usuários de fungicidas em situação difícil, pois a resistência de fungos a fungicidas causa falhas no controle químico de doenças e nem sempre existem opções de novos produtos químicos que os substituam.

As informações colhidas nos locais de origem do isolados indicam que as populações presentes nos mesmos já foram expostas a um ou mais fungicidas (tabela 2), considerando-se ainda que todos foram isolados a partir de tecidos de hospedeiros hortícolas, que geralmente recebem grande carga de fungicidas devido as características intensivas desses cultivos. Isso pode indicar que o controle químico adotado nesses locais pode estar colaborando na rápida seleção de mutantes resistentes dentro das populações de $B$. cinerea.

No caso específico dos isolados em estudo, todos foram expostos ao fungicida benomyl, e apenas um (isolado B8), de acordo com o levantamento nunca tivera contato com o fungicida iprodione no local onde o mesmo foi coletado. Os fungicidas difenoconazole e azoxystrobin de acordo com o histórico de exposição dos isolados, nunca foram utilizados, apesar de ocorrer a utilização intensiva de triazóis (como o difenoconazole) em cultivos de flores e plantas ornamentais para o controle de outras doenças fúngicas.

Nesse contexto a avaliação da sensibilidade dos isolados ao fungicida benomyl, que é um produto sistêmico específico (atua em um ou poucos processos metabólicos), vem a confirmar que a ocorrência de resistência é preocupante para essa classe de produtos (Kimati, 1995; Dekker, 1995; Moorman \& Lease, 1992). Os resultados mostraram que todos os isolados cresceram na presença de $100 \mathrm{ppm}$ do fungicida, fato 
que de acordo com Cabrini (1985) possibilita caracterizá-los como resistentes, apesar desse mesmo autor citar que a dose utilizada em aplicações no campo seja de $350 \mathrm{ppm}$. O agravante no caso dos isolados $\mathrm{B} 5, \mathrm{~B} 10, \mathrm{~B} 6, \mathrm{~B} 3$ e $\mathrm{B} 9$, foi que os mesmos apresentaram crescimento na concentração de $1000 \mathrm{ppm}$ do fungicida no meio de BDA, mostrando o alto nível de resistência ao produto.

Não houve diferença no que se refere a origem do isolado (campo ou casa de vegetação) e sua sensibilidade ao fungicida benomyl, mostrando assim que em ambos os caso a seleção de mutantes resistentes ocorre simplesmente devido ao fato da utilização intensiva do produto.

Os isolados em estudo não apresentaram resistência ao fungicida dicarboximida avaliado (iprodione), exceto o isolado B4, que apresentou crescimento na concentração de $100 \mathrm{ppm}$, apesar de $\mathrm{o} \mathrm{ED}_{50}$ desse fungicida para o isolado situar-se entre 1 e $10 \mathrm{ppm}$, similar ao $\mathrm{ED}_{50}$ obtido para os isolados $\mathrm{B} 5$ e B10. Portanto apenas um isolado apresentou resistência cruzada a benzimidazóis e dicarboximidas, sendo este um alerta para que mudanças na estratégia de controle químico do mofo cinzento sejam rapidamente adotadas.

No caso do triazol difenoconazole verificou-se a extrema sensibilidade dos isolados, com exceção dos isolados B1 e B2, que apresentaram crescimento na concentração de $100 \mathrm{ppm}$ do fungicida no meio de BDA, e no extremo de $1000 \mathrm{ppm}$ no caso único do isolado B1. Esse resultado mostra também que os fungicidas triazóis podem selecionar mutantes resistentes rapidamente em cultivos onde o controle químico de doenças predomina, não sendo portanto totalmente seguros, principalmente quando utilizados em sistemas de produção altamente intensivos como no caso das casas de vegetação, justamente o sistema de onde foram obtidos os dois isolados insensíveis. Resultados similares foram obtidos por Stehmann \& De Waard (1996) com isolados da França, Alemanha, Holanda e Israel. No Brasil Ghini (1996) encontrou para o triazol propiconazole, ligeira insensibilidade de alguns isolados de $B$. cinerea com que trabalhou em seus ensaios. 
Possivelmente, no caso de difenoconazole, a seleção de mutantes resistentes pode ter ocorrido de forma inconseqüente, ou seja, pela exposição das populações locais a esse produto em ocasiões em que o mesmo foi utilizado intensivamente no controle de outras doenças. Esse fato pode limitar o uso potencial desse produto no controle do mofo cinzento em condições de campo, como já alertou Stehmann \& De Waard (1996).

Apesar desse resultado inesperado, onde 2 isolados mostraram-se resistentes para difenoconazole, os resultados obtidos de $\mathrm{ED}_{50}$ para esse fungicida foram baixos para todos os isolados, o que mostra que o produto tem grande potencial de uso e sua estratégia de utilização deve ser revista para que não selecione-se populações cada vez mais resistentes e que porventura possam ser competitivas como as populações resistentes a dicarboximidas encontradas por Fraile et al. (1986), que esporulavam muito mais intensamente que as sensíveis.

Com relação ao fungicida azoxystrobin, que é um composto moderno ao qual os isolados nunca foram expostos, os resultados mostraram grande variabilidade quanto ao crescimento micelial "in vitro", sendo a inibição total para alguns isolados e nula para outros, o mesmo acontecendo quando analisa-se o $\mathrm{ED}_{50}$, situando-se para alguns isolados abaixo de $0,1 \mathrm{ppm}$ e para outros em $1000 \mathrm{ppm}$. Esses resultados podem indicar primeiramente que esse composto não tem nenhuma ou pouca influência no crescimento micelial "in vitro" dos isolados de $B$. cinerea avaliados, pois os isolados nunca foram expostos a esse fungicida e $70 \%$ dos mesmos apresentaram crescimento na concentração de $100 \mathrm{ppm}$ e $60 \%$ na de $1000 \mathrm{ppm}$, discordando totalmente do conceito de resistência de fungos a fungicidas, onde o surgimento de resistência é o resultado da pressão de seleção imposta pelo fungicida sobre a população de um patógeno, na qual o mesmo é utilizado de maneira intensiva (Katan, 1986; Northoever \& Matteoni, 1986; Gullino, 1989; Moorman \& Lease, 1992; Dekker, 1995; Kimati, 1995; Raposo et al., 1996). 


\section{CONCLUSÕES}

Diante os resultados obtidos conclui-se que:

1 - A caracterização morfológica dos isolados de Botrytis através da medição direta dos conídios com auxilio de equipamento eletrônico de vídeo constitui método de simples e rápida execução.

2 - Todos os isolados avaliados enquadram-se dentro da espécie $B$. cinerea, pois as médias de comprimento e largura $(10,32 \mu \mathrm{m}$ e $6,14 \mu \mathrm{m}$ respectivamente) estão dentro dos limites para essa espécie.

3 - Os isolados de B. cinerea avaliados não possuem especificidade de hospedeiros.

4 - Mantas plásticas com aditivos que bloqueiam os comprimentos de onda próximos do ultravioleta não permitem a esporulação dos isolados de $B$. cinerea "in vitro".

5 - Todos os isolados de B. cinerea apresentam resistência ao fungicida benomyl, sendo todos originários de locais onde ocorreu pressão de seleção desse fungicida.

6 - Apenas um isolado apresenta resistência aos fungicidas benomyl e iprodione, tendo também origem de local onde ocorreu pressão de seleção de ambos fungicidas.

7 - Dois isolados apresentam resistência ao fungicida difenoconazole, sendo os demais altamente sensiveis.

8 - O fungicida azoxystrobin não apresenta efeito satisfatório e conclusivo na inibição do crescimento micelial, pois os isolados nunca foram expostos a esse composto e o mesmo pode inibir o crescimento "in vitro" de alguns isolados e não inibir mesmo na maior concentração avaliada (1000 ppm) outros. 


\section{REFERÊNCIAS BIBLIOGRÁFICAS}

AGRIOS, G.N. Plant pathology. San Diego: Academic Presss, 1988. 803p.

ALMEIDA, F.R.F; AKI, A.Y. Grande crescimento no mercado das flores. Agroanalysis, v.15, n.9, p. 8-11, 1995.

ARAÚJO, A.E. Sobrevivência de Botrytis cinerea em restos de cultura, efeito de fatores do ambiente sobre o patógeno e progresso do mofo cinzento em roseiras cultivadas em casas-de-vegetação. Viçosa, 1995. 98p. Dissertação (M.S.) Universidade Federal de Viçosa.

BERGAMIN FILHO, A.; KIMATI, H.; AMORIM, L.(Ed.) Manual de fitopatologia. Volume 1: Princípios e Conceitos (3ªd.) São Paulo: Ceres, 1995. 919p.

BULIT, J.; DUBOS, B. Botrytis bunch rot and blight. In: PEARSON, R.C.; GOHEEN, A.C. (Ed.) Compendium of grape diseases. St. Paul: APS Press, 1988. 121p.

CABRINI, H.M. Ocorrência de isolados de Botrytis cinerea Pers. ex Fr resistentes a benomyl em morangos (Fragaria spp.) no Estado de São Paulo. Piracicaba, 1985. 66p. Dissertação (M.S.) - Escola Superior de Agricultura "Luiz de Queiroz", Universidade de São Paulo. 
CLARK, C.A.; LORBEER, J.W. Symptomatology, etiology, and histopathology of Botrytis brown strain of onion. Phytopathology, v.63, p.1231-1235, 1973.

COLHOUN, J. Effects of environmental factors on plant disease. Annual Review Phytopathology, v.11, p.343-365, 1973.

COLEY-SMITH, J.R.; VERHOEFF, K.; JARVIS, W.R. (Ed.) The biology of Botrytis. London: Academic Press, 1980. cap.10, p.275-301.

CROWE, F.; MOHAN, S.K.; SCHWARTZ, H.F. Other Botrytis diseases. In: SCHWARTZ, H.F.; MOHAN, S.K.(Ed.) Compendium of onion and garlic diseases. St. Paul: APS Press, 1994. 70p.

DAUGHTREY, M.L.; WICK, R.L.; PETERSON, J.L. Compendium of flowering potted plant diseases. St. Paul: The American Phytopathological Society, 1995. 90p.

DEKKER, J. Development of resistance to modern fungicides and strategies for its avoidance. In: LYR, H. (Ed.) Modern selective fungicides. Properties, applications, mechanisms of action. New York: Gustav Fischer, 1995. cap.2, p.23-38.

ELLIOTT, M.E. Self-fertility in Botryotinia porri. Canadian Journal of Botany, v.42, p.1393-1395, 1964.

EPTON, H.A.S.; RICHMOND, D.V. Formation, structure and germination of conidia. In: COLEY-SMTTH, J.R.; VERHOEFF, K.; JARVIS, W.R. (Ed.) The biology of Botrytis. London: Academic Press, 1980. cap.10, p.275-301. 
FIGUEIREDO, M.B. Estudos sobre a aplicação do método de Castellani para conservação de fungos patógenos em plantas. O Biológico, v.33, p.9-13, 1967.

FRAILE, A.; ALONSO, A.; SAGASTA, E.M. Some characteristics of Botrytis cinerea isolates tolerant to procymidone. Plant Pathology, v.35, p.82-85, 1986.

GHINI, R. Caracterização morfológica, serológica e patogênica de espécies de Botrytis que ocorrem na cultura da cebola (Allium cepa L.). Piracicaba, 1984 . 53p. Dissertação (M.S.) - Escola Superior de Agricultura "Luiz de Queiroz", Universidade de São Paulo.

GHINI, R.; BETTIOL, W. Controle físico. In: BERGAMIN FILHO, A.; KIMATI, H.; AMORIM, L. (Ed.) Manual de Fitopatologia. Volume 1: Princípios e conceitos. São Paulo: Ceres, 1995. cap. 39, p.786-801.

GHINI, R. Ocorrência de resistência a fungicidas em linhagens de Botrytis cinerea, no Estado de São Paulo. Fitopatologia Brasileira, v.21, n.2, p.285-288, 1996.

GULLINO, M.L.; ALOI, C.; GARIBALDI, A. Influence of sprays echedules on fungicida resistente populations of Botrytis cinerea Pers. on grapevine. Netherlands Journal of Plant Pathology, v.95, p.87-94, 1989.

GUNASEKERA, T.S.; PAUL, N.D.; AYRES, P.G. The effect of ultraviolet-B (UV-B: 290-320 nm) radiation on blister blight disease of tea (Camellia sinensis) Plant Pathology, v.46, p.179-185, 1996.

HANCOCK, J.G.; LORBEER, J.W. Pathogenesis of Botrytis cinerea, B. squamosa, and B. alli on onion leaves. Phytopathology, v.53, p.669-673, 1963. 
HAZENDONK, A.; HOOPE, M.; WURFF, T. Method to test rose cultivars on their susceptibility to Botrytis cinerea during the post-harvest stage. Acta Horticulturae, v.405, p.39-45, 1995.

HITE, R.E. The effect of irradiation on the growth and asexual reproduction of Botrytis cinerea. Plant Disease Reporter, v.57, n.2, p.131-135, 1973.

HONDA, Y.; TOKI, T.; YUNOKI, T. Control of gray mold of greehouse cucumber and tomato by inhibiting sporulation. Plant Disease Reporter, v.61, n.12, p.10411044, 1977.

HORST, R.K. Compendium of rose diseases. St. Paul: APS Press, 1983. 50p.

JARVIS, W.R. Managing diseases in greenhouse crops. St. Paul: APS Press, 1992. $288 \mathrm{p}$.

JARVIS, W.R. Taxonomy. In: COLEY-SMITH, J.R.; VERHOEFF, K.; JARVIS, W.R. The biology of Botrytis. New York: Academic Press, 1980. cap.1, p.1-18.

KATAN, T. Resistance to 3,5-dichlorophenyl-N-cyclic imide ("dicarboximide") fungicides in grey mould pathogen Botrytis cinerea on protected crops. Plant Pathology, v.31, p.133-141, 1982.

KERSSIES, A. Influence of environmental conditions on dispersal of Botrytis cinerea conidia and on post-harvest infection of gerbera flowers grown under glass. Plant Pathology, v.42, p.754-762, 1993. 
KERSSIES, A. Effects of temperature, vapour pressure deficit and radiation on infectivity of conidia of Botrytis cinerea and on susceptibility of gerbera petals. European Journal of Plant Pathology, v.100, p.123-136, 1994.

KERSSIES, A.; BOSKER-van ZESSEN, A.I.; FRINKING, H.D. Influence of environmental conditions in a glasshouse on conidia of Botrytis cinerea and on post-harvest infection of rose flowers. European Journal of Plant Pathology, v.101, p.201-216, 1995.

KIMATI, H. Controle químico. In: BERGAMIN FILHO, A.; KIMATI, H.; AMORIM, L.(Ed.) Manual de fitopatologia. Volume 1: Princípios e conceitos $\left(3^{n}\right.$ ed.) São Paulo: Ceres, 1995. cap.38, p.761-785.

KRUGNER, T.L.; BACCHI, L.M.A. Fungos. In: BERGAMIN FILHO, A.; KIMATI, H.; AMORIM, L.(Ed.) Manual de fitopatologia. São Paulo: Ceres, 1995. cap.4, p.46-95.

LACY, M.L.; LORBEER, J.W. Botrytis leaf blight. In: SCHWARTZ, H.F.; MOHAN, S.K.(Ed.) Compendium of onion and garlic diseases. St. Paul: APS Press, 1994. 70p.

LACY, M.L.; LORBEER, J.W. Botrytis neck rot. In: SCHWARTZ, H.F.; MOHAN, S.K.(Ed.) Compendium of onion and garlic diseases. St. Paul: APS Press, 1994. 70p.

LEACH, C.M. Sporulation of diverse species of fungi under near-ultraviolet radiations. Canadian Journal of Botany, v.40, p.151-161, 1962. 
LEACH, C.M. Ultraviolet-absorbing substances associated with light-induced sporulation in fungi. Canadian Journal of Botany, v.43, p.185-200, 1964.

LEACH, C.M. Ultraviolet-absorbing substances associated with light-induced sporulation in fungi. Canadian Journal of Botany, v.43, n.2, p.185-201, 1965.

MANNING, W.J.; TIEDEMANN, A.V. Climate change: potential effects of increased atmospheric carbon dioxide $\left(\mathrm{CO}_{2}\right)$, ozone $\left(\mathrm{O}_{3}\right)$, and ultraviolet-B (UV-B) radiation on plant diseases. Environmental Pollution, v.88, p.219-245, 1995.

MAUDE, R.B. Disease control. In: COLEY-SMTTH, J.R.; VERHOEFF, K.; JARVIS, W.R. (Ed.) The biology of Botrytis. London: Academic Press, 1980. cap.10, p.275-301.

MORGAN, D.J. Numerical taxonomic studies of the genus Botrytis. I. The B. cinerea complex. Trans. Br. Mycol. Soc., v.56, n.3, p.319-325, 1971.

MORGAN, D.J. Numerical taxonomic studies of the genus Botrytis. II. Other Botrytis taxa. Trans. Br. Mycol. Soc., v.56, n.3, p.327-335, 1971.

MOORMAN, G.W.; LEASE, R.J. Benzimidazole and dicarboximide-resistant Botrytis cinerea from Pennsylvania greenhouses. Plant Disease, v.76, p.477-480, 1992.

NICOT, P.C.; MERMIER, M.; VAISSIÈRE, B.E. Differential spore production by Botrytis cinerea on agar medium and plant tissue under near-ultraviolet lightabsorbing polyethylene film. Plant Disease, v.80, n.5, p.555-558, 1996. 
NORTHOVER, J.; MATTEONI, J.A. Resistance of Botrytis cinerea to benomyl and iprodione in vineyards and greenhouses after exposure to the fungicides alone or mixed with captan. Plant Disease, v.70, p.398-402, 1986.

NUNES, M.E.T. Solarização do solo e seleção de microrganismos antagônicos para o controle de Sclerotium cepivorum Berk., agente causal da podridão branca da cebola (Allium cepa L.). Piracicaba, 1992. 75p. Dissertação (M.S.) - Escola Superior de Agricultura "Luiz de Queiroz", Universidade de São Paulo.

RAMIREZ, A.R.; TORRES, G.A. Efecto de un plástico fotoselectivo y de una pantalla climática en la enfermedad causada por el hongo Botrytis cinerea Pers. y en negreamiento de los pétalos en un cultivo de rosas (Rosa hybrida). Agronomia Colombiana, v.12, n.2, p.127-133, 1995.

RAPOSO, R.; DELCAN, J.; GOMEZ, V.; MELGAREJO, P. Distribution and fitness of isolates of Botrytis cinerea with multiple fungicide resistance in Spanish greenhouses. Plant Pathology, v.45, p.497-505, 1996.

REWAL, N.; COLEY-SMITH, J.R.; SEALY-LEWIS, H.M. Studies on resistance to dichlofluanid and other fungicides in Botrytis cinerea. Plant Pathology, v.40, p.554-560, 1991.

RITCHIE, D.F. Effect of dichloran, iprodione, procymidone, and vinclozolin on the mycelial growth, sporulation, and resistance strain of Monilinia fructicola. Plant Disease, v.66, n.6, p.484-486, 1982.

ROTEM, J.; COHEN, Y.; BASHI, E. Host and environmental influences on sporulation in vivo. Annual of Review Phytopathology, v.16, p.83-101, 1978. 
ROTEM, J.; WOODING, B. AYLOR, D.E. The role of solar radiation, especially ultraviolet, in the mortality of fungal spores. Phytopathology, v.75, n.5, p.510$514,1985$.

SASAKI, T.; HONDA, Y.; UMEKAWA, M.; NEMOTO, M. Control of certain diseases of greenhouse vegetables with ultraviolet-absorbing vinyl film. Plant Disease, v.69, n.6, p.530-533, 1985.

STEHMANN, C.; DE WAARD, M.A. Biological activity of triazole fungicides towards Botrytis cinerea. In: LYR, H.; RUSSELL, P.E.; SISLER, H.D.(Ed.) Modern fungicides and antifungal compounds. Andover: Intercept Ltd, 1996. cap. 15, p.125-128.

VAKALOUNAKIS, D.J. Control of fungal diseases of tomato under long-wave infraredabsorbing plastic film. Plant Disease, v.76, n.1, p.43-46, 1992. 